\title{
Next-generation, personalised, model-based critical care medicine: a state-of-the art review of in silico virtual patient models, methods, and cohorts, and how to validation them
}

J. Geoffrey Chase ${ }^{1 *} \mathbb{D}$, Jean-Charles Preiser ${ }^{2}$, Jennifer L. Dickson ${ }^{1}$, Antoine Pironet ${ }^{3}$, Yeong Shiong Chiew ${ }^{4}$, Christopher G. Pretty ${ }^{1}$, Geoffrey M. Shaw ${ }^{5}$, Balazs Benyo ${ }^{6}$, Knut Moeller$^{7}$, Soroush Safaei ${ }^{8}$, Merryn Tawhai ${ }^{8}$, Peter Hunter ${ }^{8}$ and Thomas Desaive ${ }^{3}$

\author{
*Correspondence: \\ Geoff.chase@canterbury. \\ ac.nz \\ ${ }^{1}$ Department of Mechanical \\ Engineering, Centre \\ for Bio-Engineering, \\ University of Canterbury, \\ Private Bag 4800, \\ Christchurch, New Zealand \\ Full list of author information \\ is available at the end of the \\ article
}

\begin{abstract}
Critical care, like many healthcare areas, is under a dual assault from significantly increasing demographic and economic pressures. Intensive care unit (ICU) patients are highly variable in response to treatment, and increasingly aging populations mean ICUs are under increasing demand and their cohorts are increasingly ill. Equally, patient expectations are growing, while the economic ability to deliver care to all is declining. Better, more productive care is thus the big challenge. One means to that end is personalised care designed to manage the significant inter- and intra-patient variability that makes the ICU patient difficult. Thus, moving from current "one size fits all" protocolised care to adaptive, model-based "one method fits all" personalised care could deliver the required step change in the quality, and simultaneously the productivity and cost, of care. Computer models of human physiology are a unique tool to personalise care, as they can couple clinical data with mathematical methods to create subject-specific models and virtual patients to design new, personalised and more optimal protocols, as well as to guide care in real-time. They rely on identifying time varying patientspecific parameters in the model that capture inter- and intra-patient variability, the difference between patients and the evolution of patient condition. Properly validated, virtual patients represent the real patients, and can be used in silico to test different protocols or interventions, or in real-time to guide care. Hence, the underlying models and methods create the foundation for next generation care, as well as a tool for safely and rapidly developing personalised treatment protocols over large virtual cohorts using virtual trials. This review examines the models and methods used to create virtual patients. Specifically, it presents the models types and structures used and the data required. It then covers how to validate the resulting virtual patients and trials, and how these virtual trials can help design and optimise clinical trial. Links between these models and higher order, more complex physiome models are also discussed. In each section, it explores the progress reported up to date, especially on core ICU therapies
\end{abstract}


in glycemic, circulatory and mechanical ventilation management, where high cost and frequency of occurrence provide a significant opportunity for model-based methods to have measurable clinical and economic impact. The outcomes are readily generalised to other areas of medical care.

\section{Background}

Intensive care unit (ICU) patients are very difficult to manage safely, effectively and efficiently due to complex and highly variable response to therapy. The cost of intensive care and treatment has risen greatly, primarily due to aging demographics and increasing average life spans (e.g. $[1,2])$. In particular, the ability to maintain or improve the equity of access to care is increasingly important and difficult [3-8]. Thus, the major current challenge for ICU care is to improve cost and productivity. In this context, the personalisation of care to better capture the intra- and inter-patient variability in core ICU therapies offers an opportunity to make a significant impact on both the quality and cost of care. In particular, changing from current "one size fits all" protocolised care, which can be problematic in the ICU [9-11], to a "one method fits all" personalised care, based on physiological models, could provide one significant change to address the demographic tsunami of rising demand and costs.

Computational methods have revolutionised the quality and productivity of output in a wide range of industries over the last two decades, but not nearly so much in medicine $[7,12,13]$, where the ability to pay the increasing costs is declining [14]. In ICU medicine, computational physiological models offer a major opportunity to personalise care, combining medical data and model identification methods to generate a "virtual patient" that represents a specific patient in a particular state relative to the system modelled (e.g. metabolic, cardiovascular, pulmonary). In addition, computational methods can draw on an increasing range of physiological models, methods and databases, ranging from simple to detailed and multi-scale models (e.g. [15-47]), which could be used as a foundation for translating computer methods to critical care.

The overall approach relies on the ability to identify patient-specific parameters from data that are both patient-specific and time-varying, and thus manage the intra- and inter-patient variability that defines the typical ICU patient. As a result, such "sensitivities" can be the key to virtual patients and personalised model-based care, as they provide an input-output relationship that reflects patient status and response to the treatment, as well as a metric that can then be used to titrate dose and thus care. Hence, this approach defines the use of deterministic physiological models, and could thus delineate more complex anatomically and biophysically based models (referred to from now on as 'physiome models') to an informative role, while capitalising upon simpler models for immediate use at the bedside (referred to from here on as 'bedside models').

In particular, physiome models have the detail and extensive dynamics to provide significant insight into dysfunction at levels that bedside models, with their simpler single organ and/or single system dynamics, cannot [27, 30, 33, 38, 48-58]. Physiome models can also be made patient-specific. However, this task requires significant, often invasive amounts of data, which are precluded by the time and immediacy of the critical care bedside. Finally, while computational tools are advancing and becoming standardised [16, 31, 59-64], the computational intensity and number of variables can preclude 
direct, immediate use to personalise and guide care, while enhancing the ability to simulate a range of detailed dysfunction. Thus, the physiological scale and/or complexity of physiome models can limit their immediate impact and patient specificity, particularly if the patient-specific condition varies rapidly.

In contrast, the loss of detail in bedside models may hide critical information by lumping it into broader parameters or estimations. There is thus a role for both levels of modeling to integrate and inform each other. Hence, while this review focuses predominantly on the emerging use of bedside, highly patient-specific models and virtual patients, the potential links to physiome models, well reviewed elsewhere [33, 48, 57, 58, 63, 65-68], are also presented.

Bedside models that capture specific fundamental dynamics have long been applied in physiological studies, but are far less used in clinical application, particularly in critical care. However, over the last 10 years, the growing number of model-based sensors or decision support systems in critical care (e.g. [69-90]) has surged, with their successful design, validation and, in some cases, implementation as a standard of care. These results demonstrate the growing interest of using computational models to create personalised solutions to highly variable ICU patients.

Beyond their use in model-based bedside decision support, virtual patients based identified to measurement data are designed to represent the real patients. They can thus be used to design, test and compare different methods of care in silico, whether in real-time or in virtual protocol design. In particular, in silico patient-specific models provide a safe, rapid means to design, prototype and optimise treatment methods. Thus, virtual patients, and their underlying models and methods in particular, provide a tool for both design and implementation of personalised, model-based care.

In addition to safe, rapid protocol design and optimisation, virtual cohorts of virtual patients present the unique opportunity to improve on evidence-based ICU randomised controlled trials (RCTs). Those trials often focus on a single aspect of care or physiology and are thus equally often compromised by lack of generality when clinically applied in general cohorts $[91,92]$. The care of any specific dysfunction may be further confounded by a variety of related conditions, such as drug therapy or the body's own reflex responses. Together, these issues have made designing and implementing effective ICU randomized clinical trials very difficult, making it difficult for the field to move forward as a whole [10, 91-98].

Virtual patients, cohorts and trials offer the potential to advance better solutions taking into account pathophysiological condition as well as intra- and inter-patient variability in response to care. These latter changes in patient state are difficult to control in a RCT as they cannot be predicted [91, 94, 95, 97]. However, they can be easily found retrospectively in clinical data, and thus tested virtually, in silico in designing a clinical trial using a sufficiently broad virtual cohort. Thus, even before implementation one can verify a protocol is robust and safe in the face of inter- and intra-patient variability across a diverse, clinically typical cohort with multiple issues being treated. This capability would, in effect, permit a series of single patient clinical trials to be performed in silico, and to thus optimise a protocol to best manage significant variations in patient behaviour and thus performance. 
Hence, a validated in silico virtual trial platform, with associated proper virtual cohorts, would enable the elimination, or a reduction in the number, of phase II/III human trials. For regulatory submissions this potential to replace or augment human trials as an additional, accepted form of evidence is already partly realised [99, 100]. This use of virtual platforms to perform virtual trials shows the complementarity and efficiency gains possible using both in silico and clinical trials to achieve a better or best outcome in a far more efficient manner with less patient burden.

Equally importantly, since virtual trials and patients can readily include device dynamics or simulated clinical errors there is the further opportunity to better link device design and their clinical utilisation in care into both protocol and/or device design (e.g. [25, 101-105]). This point was well made in the case analysis by Viceconti et al. [100], reviewing the literature in this area, and showing two successful examples using virtual patients to develop new products. Thus, there is a critical role in product development for these types of models and methods.

Finally, and in particular, in a joint effort to develop novel devices, clinicians and medical device companies could also use them to develop optimised protocols using existing or new devices designed to fit into clinical workflow with minimal effort. This aspect is especially important wherever human factors at the interface of care and technology play a major role in protocol ease of use. The resulting improved compliance and clinical success, could significantly improve patient outcomes [106-111], by incorporating virtual patients and trials analyses.

This review examines the computational methods and modeling necessary to design virtual patients. Especially, the models and data required are reviewed, and the different levels of validation possible for the resulting virtual patients are discussed. It also notes how virtual trials could be used to design not only protocols, but also to design and test clinical trials before implementation to try and ensure more robust results from these trials. Each section explores the results to date, with particular focus on core ICU therapies managing metabolic, circulatory and pulmonary function. These three areas capture the desire to manage core ICU therapies around glycemic control, cardiovascular and circulatory management, and mechanical ventilation. In each case, variable management of these complex core therapies can be linked to worsened outcomes, increased patient length of stay and thus increased cost. Finally, before concluding, it addresses some of the future possible uses and implications of this emerging fusion of engineering and medical sciences.

\section{Model types and requirements}

A computational physiological model is a mathematical approximation of the observed physical, chemical and/or biological processes, containing certain assumptions in describing these processes. These models can vary significantly in complexity, based on the desired use, and range from simple-compartment models with few parameters (e.g. $[18,21-26,28,34-37,45,47])$ to complicated multi-dimensional network representations or finite element models for similar systems or the entire body (e.g. [15-17, 19, 20, $27,29-33,38,55,56,112,113])$.

A virtual patient model (VPM) should have: 
- Physiologically relevance.

- Clinically relevance.

- Identifiable treatment sensitivity.

And must also be:

- Identifiable from the data available at the bedside or clinical situation.

Physiological relevance of a VPM requires a fixed structure representing the relevant physiological dynamics. While no model can reflect all observed complexity of real world, to be useful, VPMs must be capable to reproduce at least the measurable physiological dynamics in critical care patients to the resolution and accuracy of the sensor readings $[18,114,115]$. The model input and output parameters should be embedded into the mathematics in the model structure describing known physiological dynamics. This requirement thus excludes black-box or generic models, such as neural networks. More directly, while it also ensures that the model captures fundamental physiology, it also sets a lower limit on model complexity.

Clinical relevance emphasises models able to be simulated in 'clinical real-time', the time between measurements and/or decisions. Model inputs should be the same as those used clinically in treating dysfunction, and outputs should be clinically measured variables relevant to guide care. Equally, it may use measurements not typically used, but for clinical uptake the advantages gained over typical approaches in terms of cost and workflow have to be justified. Hence, the model can fit directly into clinical care with inputs and outputs typically used to guide care, connected by model dynamics matching known clinical input-output responses of the physiological system, all of which ensures clinical relevance. Overall, the requirement of clinical relevance further delineates the possible model structures in size and complexity, where physiological and clinical relevance also defines an optimal model complexity sufficient to warrant a broad rollout by the clinicians.

Identifiable treatment sensitivity is a crucial part in designing a virtual patient, as well as applying a VPM to titrate care. Perfectly, care is guided by a correctly predicted patient output in response to treatment inputs. In particular, for virtual patient models, the model output responses to specified model inputs can be used. Critically, sensitivity is defined as the "rate of change" of the output values in response to changes in the input.

For example, in glycaemic control, model-based assessment of insulin sensitivity relates input changes of insulin and nutrition, to expected glycemic response [36, 37, 41, 44, 116-130], which can be monitored and its level and/or variation assessed relative to condition [88, 124, 128, 131-141]. Similarly, in mechanical ventilation, lung elastance determines how changes in the input "a controlled mechanical ventilation volume (pressure)" transfers to the uncontrolled or independent output pressure (volume) response [78-80, 142-151], where this elastance is directly related to the work of breathing and ventilator driving pressure clinicians seek to reduce in titrating mechanical ventilation [148, 149, 152-156]. Again, similar, but simpler, measures of elastance are increasingly used to titrate care $[148,155-160]$. 
In a similar manner, output measures that reflect clinical goals in cardiovascular management, such as beat to beat stroke volume or stressed blood volume [71, 161-166], are increasingly called for clinically to guide care $[167,168]$. However, current clinical measures can lack resolution and/or accuracy as they are typically estimated by surrogate measures, are typically measured only intermittently, and can require frequent recalibration during cardiovascular instability [168-173]. Model-based measures [71, 161] could be used to develop sensitivities for inotrope and/or fluid in a pharmacodynamics framework to better guide care with a high resolution model-based metric, as has been done for sedation-agitation management for example [174-176], but has not yet been addressed in this area.

Overall, these sensitivities provide only a few possible case examples. The only limitation in creating these models and defining similar sensitivities is the required physiological relevance in modelled dynamics, and ensuring the model can be practically and feasibly identified, and thus validated, with available clinical measurements [114, 177-182].

In fact, because sensitivities capture patient condition in their response to care, they can be the clinical key in defining and monitoring the intra- and inter-patient variability that defines ICU patients, and thus to guiding therapy, as seen in [117]. They could thus be regularly obtained using such models as part of clinical practice to help assess patient state and response to care, given the advantage of computational models to use clinically available data and system identification methods to obtain a clinically useful sensitivity. In particular, highly sensitive patients need less treatment input or a smaller dose, and vice versa, thus providing a better metric on which to dynamically titrate patient-specific and personalised care. Hence, a physiologically relevant sensitivity metric modeling the relation of clinical input to patient-specific output response to treament is a crucial element in improving care, regardless of whether models are used to identify this metric. In conclusion, this requirement further constrains the potential model structures and organisation, as the model must include such a sensitivity and it must be mathematically identifiable from the clinically available data [114, 177-184].

Identifiable from the data available follows immediately from this requirement and refers to mathematical criteria ensuring that the model parameters can be uniquely identified from the available patient-specific clinical data. Identifiability thus implies, that within a clinically relevant time frame a clinically relevant set of data is obtainable that can be used to identify patient-specific model parameters. More specific to virtual patients, this requirement implies it must be feasible to uniquely derive the sensitivity parameter, and all other relevant parameters, from measured clinical data. Thus, identifiable sensitivities are critical in personalising models based on patient data at any given point in time. Pragmatically, with most metrics measured only intermittently and limited real-time data, only limited parameters can be uniquely identified. This limitation places an upper limit on model complexity, at least for direct, immediate use at the bedside (e.g. [70, 121, 177, 180-182, 185]).

This approach is also a minimal approach to the number of variables identified. Insisting on unique identifiability combined with typically limited or sparse data also helps ensure that a model is not over fit to the data. In particular, over fitting can be a major issue when more than one or a few model variables are identified as there is 
trade-off between them, even if they are uniquely identifiable resulting in a model that does not accurately capture the dynamics or predict well. There are formalised analysis approaches using information criteria and/or practical identifiability analysis to aid in model selection and avoid over fitting and/or trade-off [177, 184, 186-190].

In contrast, increased model complexity can add clinical relevance and detail. Thus, models incorporating several to multi-million degrees of freedom can offer great insight into metabolic, pulmonary, cardiovascular, and, indeed, whole body systems (e.g. [15$17,19,20,27,29-33,38,49,56,65,67,68])$. However, especially given limited available bedside data, their parameter sets cannot necessarily be identified in real-time for use at the bedside in personalised care or virtual patients (to guide care) at this point. Importantly, this limitation does not stop the accrual of data to create a more patient-specific version of a more complex model, but does limit their immediate bedside use for guiding care, and thus the ability to create virtual patients, as well.

Given a suitable set or sets of parameters reflective of real patients, physiome models could have a role in protocol design in simulating real patient conditions with the required high or multi-scale level of detail [32, 33, 38]. Longer term, as care and data progress, enough data could accrue to create a patient-specific, potentially multi-scale bedside version of the physiome model $[57,191]$, particularly where there are emerging approaches to adapt model complexity to data availability that would unify this transition [192-194].

Overall, a VPM must contain all clinically relevant physiology and physiological dynamics to adjust treatment. Clinically relevant inputs and outputs including an identifiable sensitivity parameter must be included in the model structure. Over time, the evolution of these sensitivity profiles can quantify the intra-patient variability of the patient's evolution over time as well as inter-patient variability. These requirements allow one to design VPMs, create personalised protocols in silico, and clinically implement those protocols to personalise care.

Figure 1 depicts a metabolic model and its defining equations developed to create virtual patients and design glycaemic protocols [121]. Model inputs include parenteral $(P N(t))$ and enteral $(P(t))$ nutritional carbohydrate uptakes with appropriate appearance

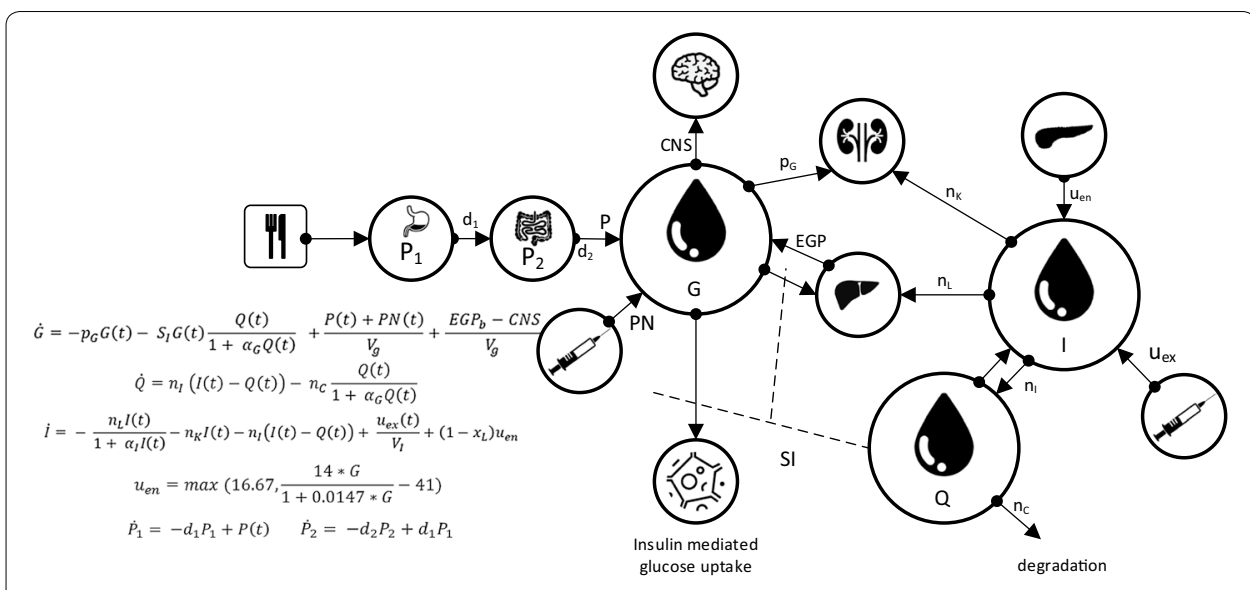

Fig. 1 Glucose-insulin pharmacokinetic and pharmacodynamics model used for virtual patients 
dynamics, and the exogenous intravenous insulin input and its kinetics $\left(u_{e x}(t)\right)$. The VPM structure comprises all relevant nutrition dynamics and insulin kinetics. The pharmacodynamics equation for glycaemia, $G(t)$, combines these inputs with the insulin sensitivity, $S_{I}(t)$, to deliver a patient-specific glycaemic output response. Depending on data density insulin sensitivity can be identified hourly or more frequently. Patient specific dynamics and their evolution over time can then be reproduced [36, 99, 116, 118, 133, 195, 196].

Similarly, Fig. 2 shows a simple pulmonary mechanics model that can be used to identify breath-specific and patient-specific elastance, the volume (or pressure) response to a controlled pressure (or volume) input in mechanical ventilation. This specific model has been validated on clinical data for both sedated and spontaneous breathing patients [142, 197-200]. As noted, the inputs are volume and flow (or pressure) with concomitant pressure (or volume and flow) independent outputs that are a function of the patient response to ventilation. The model sensitivity determined from these inputs is elastance as the sensitivity, discussed previously, which is used to guide care towards ventilation of patients at, in this specific example, minimal pulmonary elastance.

Last, Fig. 3 shows a specific model and equations for a model-based measure of stroke volume (SV) [161], based on similar prior models [201, 202]. Real-time SV has recently been identified in a consensus statement as a primary variable that would aid the guidance of circulatory management [167]. From this measure, a simple pharmacodynamics models could be created using a standard approach validated in sedation management and other areas, including sensitivities to both inotrope and fluid therapy

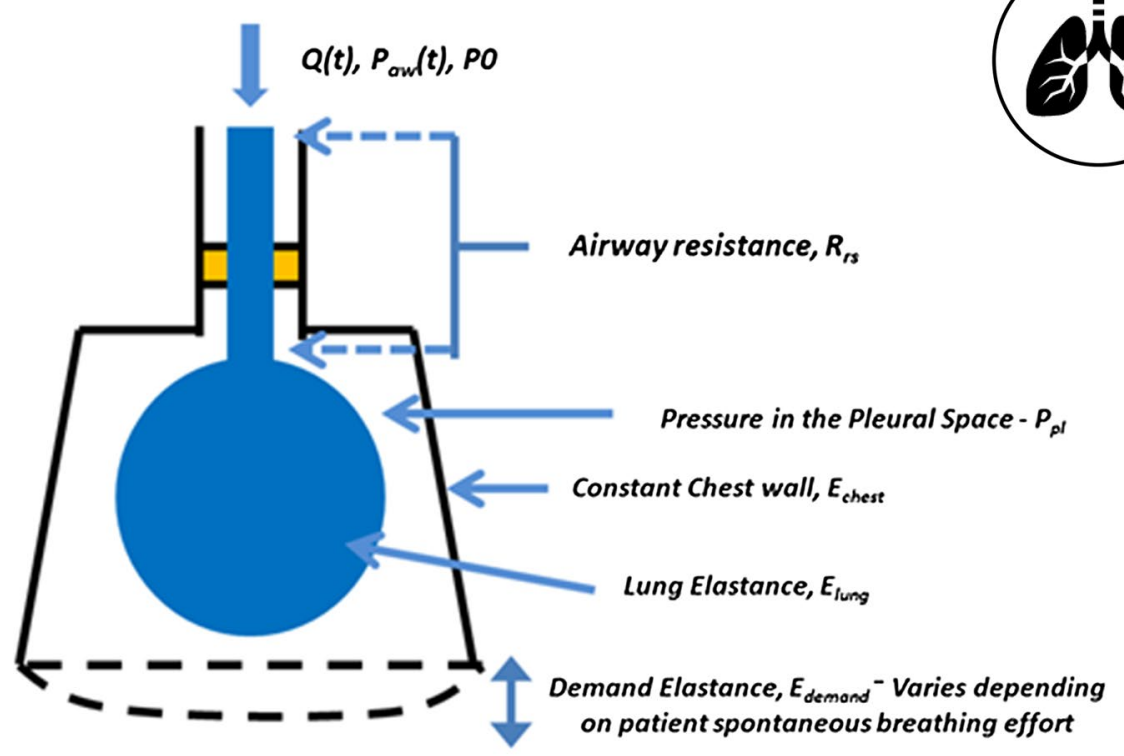

$$
P_{\text {ow }}(t)=\left(E_{\text {lung }}(t)+E_{\text {chest }}(t)+E_{\text {demand }}(t)\right) \times V(t)+R_{r s} \times Q(t)+P O
$$

Fig. 2 Simple respiratory system ventilation model, where it is modelled as a combination of resistive and elastic components 


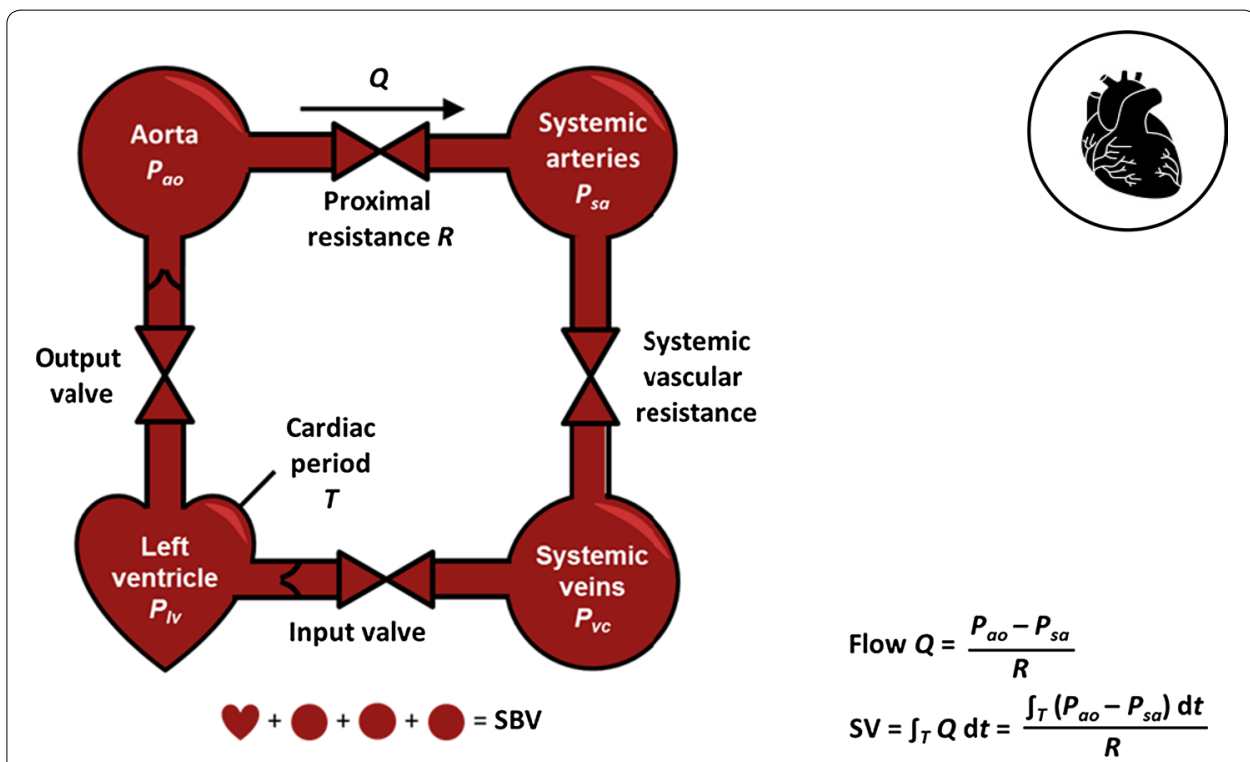

Fig. 3 Minimal cardiovascular circuit model used to identify beat-to-beat stroke volume (SV) or/and stressed blood volume (SBV), from which sensitivities to therapy could be developed to help guide care

to aid cardiovascular and circulatory management. It could thus offer a new avenue of addressing key questions in circulatory management around assessing and managing fluid responsiveness and inotrope dosing that are currently major issues in the field (e.g. $[167,203-209])$. Similarly, once there is a validated model with a uniquely identified sensitivity, a virtual patient can be created to design and/or implement personalised, modelbased care.

When considering physiome models, each might be linked over time to these bedside models. Metabolic behaviour in Fig. 1 would, for example, be better informed by both circulatory and metabolic systems models, particularly in addressing diabetes. Pulmonary mechanics in Fig. 2 are tightly coupled with circulatory dynamics, and, equally, more detailed representations including outcome gas exchange [79, 210, 211] not addressed in just considering elastance and driving pressure, but related to outcome organ function. Finally, circulatory and cardiovascular management using models, like the one in Fig. 3, would be enhanced by more detailed circulatory dynamics in place of lumped parameters. Hence, a hierarchy exists, where this review focuses primarily on the virtual patient and thus the simpler modeling approaches, while noting that the overall idea of reproducible models used at the bedside will readily generalise to other levels and scales of models [57], as data becomes more dense and available.

In summary, the three core areas in this review all have models and/or emerging model-based measures that could be fitted into known model structures. The overall in silico or model-based approach, already in use in glycemic control and metabolic diagnostics, can provide a template for use in other areas, where first pilot and clinical trials are commencing in the pulmonary case [77] and yet to emerge to the best of the authors' knowledge in the cardiovascular case. Hence, the model definition provided in this section provides a means of evaluating models relative to available clinical data and the clinical application. 


\section{Data required for virtual patients}

As illustrated in Fig. 4, virtual patients are derived directly from VPM and clinical data via system identification of model parameters ("Model types and requirements" section). To identify the desired sensitivities, data is required for all relevant inputs, e.g. for glycaemic control insulin and all forms of nutrition, for mechanical ventilation pressure/ volume inputs and positive endexpiratory pressure, and for cardiovascular monitoring the stroke volume and other measures of circulatory pressures and/or flows. Also necessary are measurements of the clinically relevant and modelled output (e.g. glucose, volume/pressure, and stroke volume or other metric, respectively).

A wide range of methods is available to obtain a model-based sensitivity from this input-output data (e.g. [18, 118, 123, 212-222]). Tracked over time, it reveals the evolution of this patient-specific sensitivity to care and patient condition. This trajectory of sensitivity values, captured as a virtual patient, can consequently be employed to calculate how new ways of administering interventions and care (e.g. insulin and/or nutrition) might lead to new, optimized, output results (e.g. blood glucose levels and/or variability), which in turn can be linked to clinical outcomes (e.g. [153, 223-233]).

A further important aspect of VPMs is ensuring relevant physiological and clinically observed dynamics are captured accurately. If the pathophysiological state of patients evolves slowly over time, then these parameters or sensitivities need only be identified at the same pace or slightly faster rate. Similarly, if clinical interventions only vary slowly or their effects can only be captured slowly due to limited or highly invasive measurements, then model parameters should be adapted at a similar rate. There is thus a balance between clinical measurement/intervention rate, and the underlying rate of physical change that can be observed with the data available, and thus identified and validated.

Dysfunction in most ICU patients is typically characterised by fast changing dynamics demanding frequent adjustments of care compounded by, or alongside, significant

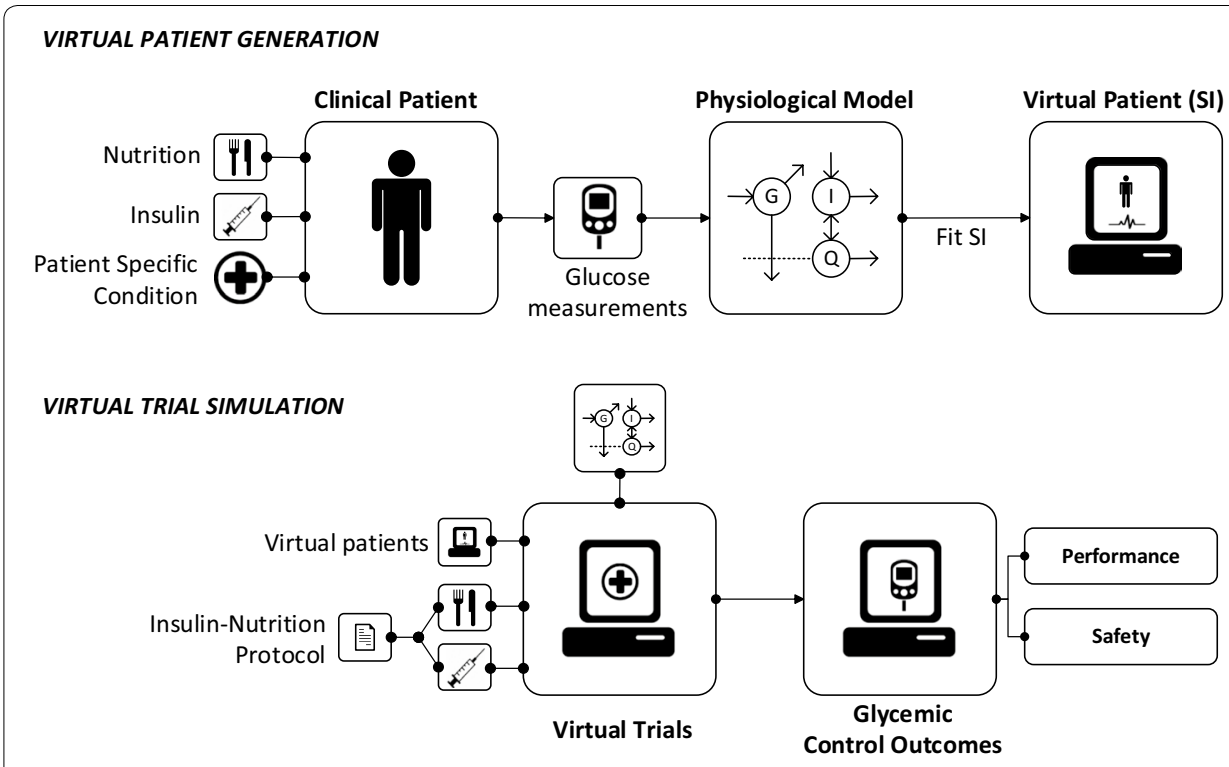

Fig. 4 Virtual patient and cohort creation (top) and virtual trials process (bottom) for a metabolic model and system, but generalisable in model and inputs/outputs to any other similar case 
inter-patient variability in response to care. Thus, the data must be measured with a frequency enabling the identification of these differences in level and rates of evolution in a clinically useful timeframe. However, measurement frequency is subject to a trade-off on clinical workload and quality of care, especially if the data must be manually obtained, entered and/or managed [106, 234-236]. Thus, such an approach also opens the next technological door towards electronic and automated sensing, and eventually, closed loop care systems, as recently emerging with the artificial pancreas in type 1 diabetes [237-249].

Thus, input and measured data must be available at rates appropriate for successfully revealing the observed and model dynamics, which in turn opens new technological opportunities around continuous or automated sensing and data management. If measurements are not frequent enough, the model may miss important changes in patient state and trends to be useful in guiding care. Fortunately, many clinical sensors currently deliver data more frequently than necessary, e.g. cardiovascular pressure catheters providing pressure signals almost continuously, or respiratory pressure and/or flow waveforms are equally sampled at 100-400 samples per second. Further, more and more ICU sensors provide electronic interfaces, allowing automated data access at appropriate rates using standard data acquisition (e.g. pressure signals from a catheter or glucose measurements from a continuous glucose monitor (reviewed for ICU in [250]), significantly reducing the data acquisition workload [234, 251]. Hence, increasingly, it is "only" required to guarantee, that the combination of models and data bring about accurate model-identified estimates of the physiological sensitivities and its evolution.

Overall, it can often be assumed that there is likely to be sufficient and relevant data for all the core areas of care considered here, for which a virtual patient and model-based approach might have impact. Thus, rapidity of data acquisition is not an issue. Equally, it is important to understand the error and/or bias in any sensor to avoid over fitting a parameter, providing an upper limit for the resolution of identified parameters and number of model dynamics required. This upper limit can be informed a priori using existing methods [186, 187], and should also be informed by the underlying knowledge of the physiology. Thus, the size of the model and the ability to identify it remain an issue, but one that increasing data, along with coupling to the bedside scale models discussed in more detail in this review, could be ameliorated in a multi-scale approach [191].

Finally, despite increasing ease to gather data, there is also increasing need for data by researchers. This issue creates the opportunity for data sharing to significantly enhance potential research gains using emerging big data informatics and machine learning, for example. Thus, this review would recommend that groups with large databases consider how data could be safely and ethically shared as is done for example by the ELIXIR database and others in the EU [252, 253].

\section{Virtual patients, virtual cohorts, and their validation}

To this point, the needs and requirements for models, parameter identification methods, and measured clinical data are covered. The metabolic management space is the furthest, having profited from decades of modelling around understanding, diagnosing and controlling diabetes mellitus in outpatients (e.g. [18, 41, 99, 129, 196, 241, 242, 245, 248, 254-257]). Pulmonary modeling for managing mechanical ventilation is emerging 
towards its first RCT [77], although many models exist (e.g. [28, 78-80, 211, 258]), and cardiovascular and circulatory management is more complex and still emerging. Hence, this section has more focus on the validation of metabolic models and systems, as an example, with broader reference to the needs and requirements applicable to any such model in other areas.

\section{Virtual patients}

Figure 4 shows how virtual patients can be created, where the trajectories of modelbased sensitivities offer significant clinical and/or physiological insight independent of any use in the model. It is important to understand virtual patients represent those patient's specific responses, implicitly encoded by the model structure and parameter values identified from the patient data. If the model structure is appropriate and parameters accurately identified, the outputs will reflect patient-specific condition and evolution. Thus, comparing these trajectories over different conditions offers added insight, e.g. comparing patients with and without a given drug therapy [25]. While, to date, such analyses are limited, the growth of accessible data should enable much more rapid use of model-based sensitivities for research insight and in virtual patients to improve care.

In metabolic systems, insulin sensitivity trajectories have captured the impact of other drug therapies [132, 259], provided insight into the evolution of patient condition over time and thus provided hints how to target better treatment [131, 133, 139], and diagnosed the absence of sepsis [88]. In pulmonary mechanics model-based elastance has been investigated to reveal the impact and effect of recruitment manoeuvres and how they decline over time [152, 260,261]. The impact of different breathing modes and recruitment manoeuvres [80,142, 147, 261-263], where clinically assessed, simpler elastance metrics have been insufficient [264]. In the cardiovascular area, model-based methods of determining beat to beat stroke volume or stressed blood volume [71, 161], and other more detailed lumped parameter physiological models used for real-time diagnosis (e.g. [265-268]), have been created with the eventual use to study the effect of inotrope, dosing fluid management with a long term goal of having virtual patients emerge in this area, where further patient-specific guidance would add significant value to a difficult clinical problem [162, 167, 269].

Thus, VPMs and derived virtual patients create an opportunity for defining and optimising new protocols and consequently methods to optimise care. In this way, several protocols for metabolic control have been optimised, at least in part [36, 72, 76, 84, $90,128,239,270-273]$, and some have gone on to show clinical results very close to those simulated before implementation [90, 274, 275]. Virtual patients can thus be used to enhance protocol development, as well as to create patient-specific protocols using direct modeling and, in some cases, management of the inter- and intra-patient variability in risk-based treatment decisions $[72,84,85,89,119,120,128,270]$. Particularly in the glycaemic control, failure to manage patient variability due to the application of fixed protocols has been shown to contribute significantly to the failure of large clinical trials [117]. This evidence is in strong support of the use of virtual patients to develop protocols that directly manage patient variability in ways clinically derived protocols cannot.

Equally, virtual patient models can also be used to analyse existing protocols. Numerous possibilities include testing protocol variations, including timing, sensor errors, 
errors in dosing, other inputs, and patient variability [36, 101-103, 117, 135, 276], or even the development of robust sensor data management and alarms [277, 278]. In particular, it should be noted that while sensor models are not in the scope of this review, there is a rich literature on validated sensor and device models, which can play a key role in these simulations (e.g. [118, 279-291]). Virtual patient models can also be used to test model assumptions, such as the impact of fixed, unidentifiable physiological model parameter values on performance and/or control when they cannot be identified from the available clinical data [36, 101, 292-295]. Hence, virtual patient models can test model assumptions, the impact of expected or unexpected physiology, the impact of delivery or sensing technologies, or any combination.

Finally, it might be worthwhile to note that all these methods used to create virtual patients have a sound basis over decades of physiological modelling and parameter identification of physiological parameters for research studies. The concept of virtual patients, which to the best of the authors' knowledge was first introduced for designing a protocol for a standard of care in [272], has significantly extended these early works and can be found in other patient simulators and models (e.g. [85, 99, 102, 123]). In fact, a recent analysis about future ICU research noted its current critical failures, mainly, too often syndromes and specific cohorts are studied that do not generalise and that perhaps in the future "single patient trials" may become more important [91, 93]. Virtual patients capture these single patient trials in silico, and can be used in real-time for decision support in personalised, model-based protocols, uniquely treating each individual patient in a personalised "one method fits all approach" or single patient trial.

\section{Virtual cohorts}

Virtual cohorts are simply collections of virtual patients. Since virtual patients can be derived from any group of useful and clinically relevant patient data, virtual cohorts can be designed to be as specific, or, more relevantly, as general as possible. Thus, a virtual cohort can be derived from any such collection of relevant patient data. The data should be as representative and complete as possible of the targeted treatment group or cohort, while ensuring it contains all reasonably expected patient states, patient dynamics and evolution of patient condition, which might occur in practice. Thus, broad and typical, where many randomised trials have very focused and thus potentially atypical cohorts [91].

For example, a glycaemic control virtual cohort with none of the rapid rises or changes in insulin sensitivity that lead to hypoglycaemia and its associated risks in treatment and outcome, would not be representative of observed clinical results to date. The same would hold for the other areas of analysis considered here, including but not limited to sudden desaturation events or the impact of proning, a controversial topic [296, 297], in ventilation on the overall effective respiratory elastance, or the impact of sudden changes in circulatory dynamics. It is the authors' experience in applying virtual patient models to design protocols and clinical trials, and then implementing them in model-based care, that, in fact, to ensure patient safety and protocol robustness, it is better to slightly over represent outlying cases than to under-represent or miss them.

Consequently, a virtual cohort should cover all clinically relevant patient dynamics observed in care, similarly to the physiological model and clinical data that should 
represent all relevant patient dynamics observed in care. Failure to comply with this constraint implies a potentially skewed protocol design due to the missing dynamics and thus imposes additional risk to either safety or performance during deployment of a protocol created using this approach. Equally, a skew towards outliers or a certain behaviour that is not representative of the treatment cohort itself can also provide bias in the protocol. This choice may be acceptable as long as all dynamics are represented as any in silico design could ensure robustness across those dynamics in the virtual patient cohort. Thus, these cohorts and episodes should be broad enough in patient numbers and patient diagnosis to capture all clinically observed dynamics, particularly outlying effects or cases. They must also accurately represent what would be found in ICU practice, so that simulations of these virtual cohorts implementing virtual trials yield results that match what is seen, or would be seen, in practice.

The research relevance of this latter point is important as a recent analysis on the state of ICU research noted that clinical trials with limited cohorts often do not generalise to broad cohorts and typical care situations [91]. Virtual cohorts enable the design of effective, general protocols for the typically diverse cohorts seen in practice, yielding a model-based and personalised "one method fits all" form of care that robustly translates to all or most patients [273, 298]. The resulting protocols thus offer the ability to design and conduct clinical trials with greater confidence in the ability of the results to generalise.

Virtual trials (Fig. 4) give model-based indications of likely safety and performance outcomes for protocols tested on a particular virtual cohort. Virtual trials require either a treatment independent sensitivity, such as insulin sensitivity in the glycaemic control case, or some way of capturing changes in this sensitivity with time and/or treatment interventions. In the case of the pulmonary modelling, a short or longer recruitment manoeuvre that results in improved lung recruitment will change the underlying elastance sensitivity, or volume response to pressure (or vice versa), but can be used in a protocol to identify a current state and select care. Capturing how these changes in virtual patient based virtual trials on a per-patient or cohort basis is the subject of ongoing work in the field.

\section{Validation: ensuring the model is "Good"}

The critical question with any modelling approach is how to verify if the model is valid in capturing the clinically observed relevant dynamics? Fitting a model to data does not guarantee the identified sensitivity parameters and resulting patient-specific model will accurately capture the patient-specific response to care. Due to model complexity, currently the only practical approach to test validity and thus the identified, patient-specific model parameter values is to test if the identified model accurately predicts the outcome in response to a new clinical input. This test clearly shows whether the patient-specific model and parameter values have accurately captured the patient-specific condition. But, how do we best and with least effort validate such virtual patients and models in practice?

This review proposes three increasingly rigorous validation tests to assess the validity and thus clinical utility of a model and virtual patient cohort: 
- Patient level A patient-specific model can be identified form a series of clinical data at a given moment in time, from which the outcomes from subsequent clinical inputs can be simulated. Predicted, patient-specific outputs are compared to the measured patient data testing the predictive validity of the virtual patient model. This test assumes an accurate identification resulting in accurate prediction of the patientspecific sensitivity and patient dynamics. However, since patient-specific condition changes over time, within the range of intra-patient variability this test thus validates the patient-specific VPM dynamics.

- Cohort level before-after Given a virtual cohort a specific protocol can be simulated and outcomes compared to prior or later application of the protocol in clinical use. Comparing statistical cohort results (median and variability) and individual patient median results assesses if virtual patient model accurately captures cohort dynamics (median and variability) and the central tendency of the individual patients in that cohort. This test validates the models and parameter identification methods over a cohort and specific, individual virtual patients over an entire episode or stay, and thus the overall approach. However, it does not validate specific patients beyond central tendency of their outputs.

- Cohort level cross validation This validation test uses data from multiple clinically matched cohorts (typically by severity score, diagnosis or other patient metric) to create matched virtual cohorts. These virtual cohorts can be tested on the original protocol they were given, providing a "self validation" assessing model errors, as above. Cross validation tests the virtual patients of Cohort A on the protocol given to Cohort B with results compared to the clinical results for the (matched) Cohort $\mathrm{B}$, and similarly so for any other cohorts (C, D, etc.). The other cohorts are treated similarly. Figure 5 illustrates the approach. The quality of outcome at the cohort and per-patient levels of each cross validation test can be compared to clinical data from a clinically matched and thus equivalent cohort. These tests assess the independence of the identified patient-specific, model-based sensitivities from the data used to create these virtual patients, including their ability to accurately model the underlying

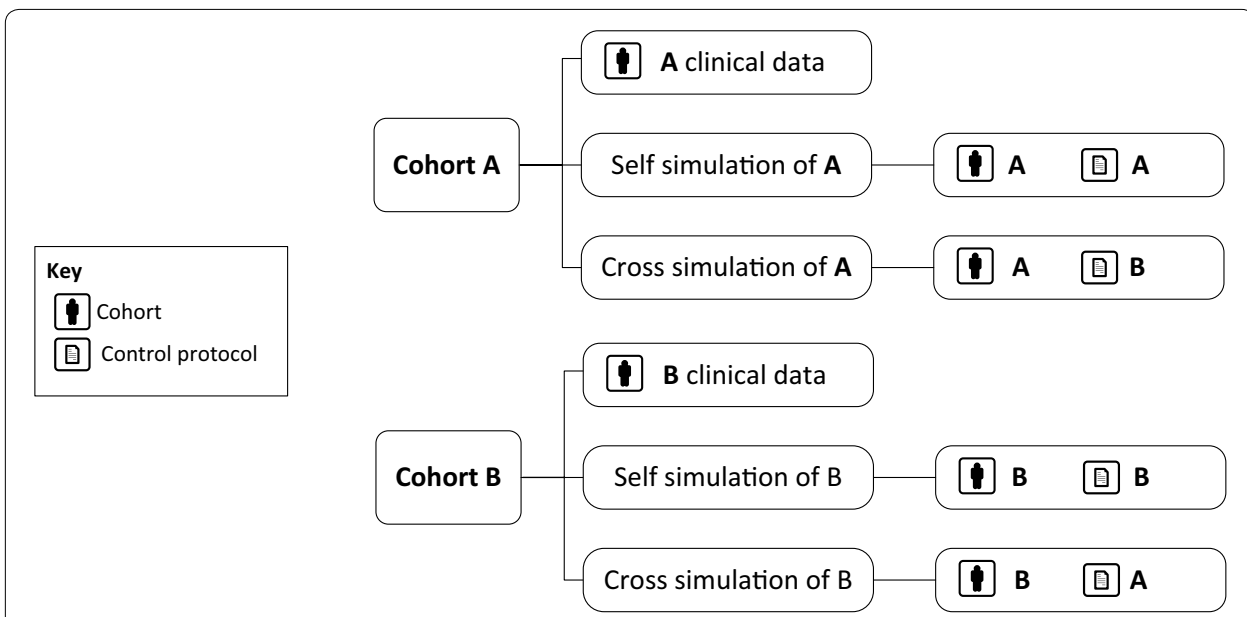

Fig. 5 Virtual trial scheme for self- and cross validation example for the two cohorts and protocols 
patient dynamics so they provide the expected/same results, as the matched clinical cohort when treated with another protocol.

These three validation tests assess the validity of the model, the identified patient-specific sensitivity parameters, and the ability to accurately design protocols that clinically produce the same results seen in silico at both the patient and cohort levels. The cohort level allows accurate in silico estimation of clinical performance of the protocol when used. The patient level allows accurate evaluation of safety or outlying events, which occur to selected patients in a cohort. Together, these validation tests ensure virtual patient and model validity by ensuring that using them to design a protocol will deliver the same results clinically.

Examples of the first form of validation are found in [121] and have been applied in multiple studies $[36,123,276]$. Importantly, these validation tests do not focus on model fit to data, but the ability to adequately predict a wide range of clinical outcome metrics, or simply, the ability of the model to generalise. Similarly, pilot trials can be used in this form of validation, where targeted clinical data is collected prospectively using a model and protocol (e.g. [89, 299]).

At the patient level, predictions are only as accurate as the ability to capture variation in patient state over the addressed relevant time interval. Assessing the range of error allowable or likely for intra-patient variability can be done, for example, using stochastic models that provide estimates of the range of intra-patient variability $[117,120]$. There is also significant work in the area of type 1 diabetes modeling assessing variability of model parameters including physiological and behavioural changes using Bayesian virtual patients and cloning and statistical models [300, 301], which are part of the validation of the Padova type 1 diabetes simulator [99] recently approved for use in some regulatory submissions. However, since many intra-patient variations over a reasonable interval are relatively small, patient level prediction is thus a basic first validation step of the model and sensitivity values, because the ability to capture physiology by predicting outcomes to clinical inputs is a critical first element.

Cohort level before-after validation has only been presented, to the authors' best knowledge, twice [90, 274]. The main desired goal is to predict cohort level median response and variability (e.g. interquartile range and/or 90\% range). This requirement thus wants a model to capture the first and second order cohort level statistics critical to understanding protocol performance and overall risk, and, ideally, also the per-patient central tendency (e.g. median) statistics, as well.

Successful, before-after validations illustrate how in silico protocol design can accurately capture the outcomes of clinical trials, well in advance of the actual clinical use, enabling far faster and safer protocol design. Hence, this form of validation also illustrates the potential of virtual patients in designing safe, effective and personalised new treatment approaches. While such models are now emerging in other areas than glycemic or metabolic control, the requirements noted above could be seen, at this point, as being general across these areas.

Cohort level cross validation has only been demonstrated twice [116, 302], and could be viewed as the most rigorous form of model validation, requiring extensive data and trials in the area even to enable the test. Good results comparing both cohort and 
per-patient median response in this study validated the underlying model assumptions, showing the identified sensitivity parameter, in this case insulin sensitivity [116], was an accurate representation of patient condition and evolution at a cohort and patient level, independent of the clinical inputs used to identify that value. The second case presented this evidence across three independent ICU cohorts and different clinical practices for two protocols, one model-based and one local clinical protocol [302]. These outcomes thus more conclusively validated these models, methods, and overall virtual trials methodology.

In summary, this section presents three forms of model validation, trying to answer the essential question of "how good are the model and virtual patients created?" The three tests presented are in increasing order of rigor, and provide increasing levels of confidence to a user that the model and virtual trial outcomes will be the same when used in clinical practice. They also require increasing data from pilot or clinical trials, and thus would be obtained as a field matures, where, in this case, the metabolic modeling area is mature and the cardiovascular area is still emerging only now at the first level, for example. However, the overall tests themselves are general and should be applicable to any virtual patient model, method, and eventual virtual trial.

\section{Further and future possible implications: economics and decision making}

This review has presented virtual patients primarily from the viewpoint of their technical potential to solve medical problems in terms of their use to develop, design and clinically apply novel therapeutic approaches. The ability to use their underlying models and identified patient-specific parameters as model-based sensors better assesses patient state and can predict the potential response to therapy. However, these technical and clinical advantages might also flow-on to significantly affect the economics and decision making in health care.

In addition, given the ability to reasonably predict the response to an intervention, whether in real-time or over a virtual cohort, then it would be possible to ascertain the cost of care or required change in care. Any intervention has a cost, including the personnel required to administer it. For glycemic control, these costs may be relatively low for glucose sensing and insulin, although the time cost of care can be high [234]. On the other hand, the cost and clinical impact of catheters in cardiovascular monitoring (e.g. [303-307]) or added cost of each mechanically ventilated patient day [308] can have large impacts on the cost and outcome of care, so the ability to optimise their use and improve outcomes could help alleviate cost pressures. Studies have associated improved levels of glycaemic control with net cost savings $[309,310]$, at least some of which might be predicted in simulation. Hence, the ability to understand the number of interventions and devices required for a cohort, using virtual trials and locale specific cohorts, could lead to better understanding and/or predicting some of the significant contributors to the cost of care. Overall, as such frameworks emerge, it could become possible to assess, monitor, and track the cost of ICU care in particular settings. A virtual trial framework for protocol design may consider not only for improvements in care and outcome, but also optimisation of resource utilisation in a specific setting.

Finally, as virtual patient methods with the ability to model and predict the response to care improve, it may become possible to determine the impact, or futility, of care. In 
glycemic control it is already possible to assess a resistance to insulin therapy in some patients. While hyperglycemia is well associated with increased risk of poor outcome and mortality, it does not in any way imply futility for all care of that patient. However, in future, across multiple organ systems and modes of care, it may become more possible to assess overall patient outcomes, creating both the opportunity to avoid prolonging ineffective care, as well as generating significant ethical debate around the legitimate uses and scope of technology in decision making.

\section{Conclusions and overall summary}

The combination of engineering and computer modelling approaches has revealed great potential in intensive care medicine. Easier, more frequent access to data allow increasing ability to utilise computation to enable the model-based design and implementation of better protocols/procedures enabling improved, personalised care. The methods used to design virtual patients and cohorts reviewed in this article are the emerging tip of a much larger iceberg in personalised, and potentially increasingly automated, care in the ICU, and eventually in less acute and out-patient care.

Personalised, patient-specific precision medicine is widely tipped as the next major advance in health care. The transition from "one size fits all" protocols with little or no adaptation to manage intra- and inter-patient variability to personalised, time-varying "one method fits all" approaches will enable better care and thus improved outcomes compared to current non-computerised care, which lacks the capability to process the available clinical data to achieve these goals. Hence, one immediate and critical key element in achieving these goals is the development and increasing use of robust, accurate virtual patient models and methods addressing major areas of ICU and chronic disease, including the metabolic, pulmonary and cardiovascular systems, as reviewed here.

In particular, the merger of increasingly available clinical data and engineering modelling can create virtual patients and cohorts, which, properly validated, can be used to analyse, design and optimise care, while maximising safety and performance. They also offer the opportunity to test the potential of new devices and drug therapies in silico, far faster and more safely than via a clinical trials based approach, saving time and reducing risk. This review has thus delineated the types and structure of models necessary, including the need for key sensitivity parameters, defined the required and increasingly easily obtained clinical data, and, critically, proposed three levels of model validation to ensure the resulting virtual patients and cohorts are safe, accurate and clinically relevant. The overall result creates a clear outline of the state of the art in each area and their interaction.

In future, virtual patient cohorts might be readily collected and curated from increasingly deployed central electronic patient data management services, for open access use by researchers, industry and/or regulatory bodies. They enable not only in silico testing of new treatments and/or devices, but also the potential for standard in silico testing for regulatory approval. In addition, more rapid design and optimisation of personalised care approaches may well yield significant economic and social benefits from improved productivity in care and patient outcomes. 


\section{Authors' contributions}

JGC led the writing and organisation of this manuscript, and all authors contributed to the conception, further writing, revision and editing of this review article. All authors read and approved the final mnauscript.

\section{Author details}

${ }^{1}$ Department of Mechanical Engineering, Centre for Bio-Engineering, University of Canterbury, Private Bag 4800,

Christchurch, New Zealand. ${ }^{2}$ Department of Intensive Care, Erasme University of Hospital, 1070 Brussels, Belgium. ${ }^{3} \mathrm{GIGA}$ In Silico Medicine, University of Liege, 4000 Liege, Belgium. ${ }^{4}$ Department of Mechanical Engineering, School of Engineering, Monash University Malaysia, 47500 Selangor, Malaysia. ${ }^{5}$ Department of Intensive Care, Christchurch Hospital, Christchurch, New Zealand. ${ }^{6}$ Department of Control Engineering and Information Technology, Budapest University of Technology and Economics, Budapest, Hungary. ${ }^{7}$ Department of Biomedical Engineering, Institute of Technical Medicine, Furtwangen University, Villingen-Schwenningen, Germany. ${ }^{8}$ Auckland Bioengineering Institute, University of Auckland, Auckland, New Zealand.

\section{Competing interests}

The authors declare that they have no competing interests.

\section{Ethics approval and consent to participate}

Not applicable.

\section{Publisher's Note}

Springer Nature remains neutral with regard to jurisdictional claims in published maps and institutional affliations.

Received: 9 October 2017 Accepted: 12 February 2018

Published online: 20 February 2018

\section{References}

1. Halpern NA. Can the costs of critical care be controlled? Curr Opin Crit Care. 2009;15(6):591-6.

2. Shorr AF. An update on cost-effectiveness analysis in critical care. Curr Opin Crit Care. 2002;8(4):337-43.

3. Halpern SD. ICU capacity strain and the quality and allocation of critical care. Curr Opin Crit Care. 2011:17(6):648-57.

4. van Exel J, Baker R, Mason H, Donaldson C, Brouwer W, EuroVa QT. Public views on principles for health care priority setting: findings of a European cross-country study using Q methodology. Soc Sci Med. 2015;126:128-37.

5. Orsini J, Blaak C, Yeh A, Fonseca X, Helm T, Butala A, Morante J. Triage of patients consulted for ICU admission during times of ICU-bed shortage. J Clin Med Res. 2014;6(6):463-8.

6. Truog RD, Brock DW, Cook DJ, Danis M, Luce JM, Rubenfeld GD, Levy MM, Task Force on Values E, Rationing in Critical C. Rationing in the intensive care unit. Crit Care Med. 2006;34(4):958-63 (quiz 971).

7. Baumol WJ, De Ferranti DM. The cost disease: why computers get cheaper and health care doesn't. New Haven: Yale University Press; 2012

8. Dombovy ML. US health care in conflict-Part I. The challenges of balancing cost, quality and access. Phys Exec. 2002;28(4):43-7.

9. Amerling R, Winchester JF, Ronco C. Guidelines have done more harm than good. Blood Purif. 2008:26(1):73-6.

10. Fernandez A, Sturmberg J, Lukersmith S, Madden R, Torkfar G, Colagiuri R, Salvador-Carulla L. Evidence-based medicine: is it a bridge too far? Health Res Policy Syst. 2015;13:66.

11. Naylor AR. Interventions for carotid artery disease: time to confront some 'inconvenient truths'. Expert Rev Cardiovasc Ther. 2007;5(6):1053-63.

12. Economist T. Patient, heal thyself. London: The Economist; 2011. p. 2.

13. Micklethwait J. Taming leviathan. London: The Economist; 2011. p. 6.

14. OECD. FOCUS on health Spending@ OECD health statistics 2015. OECD Health Stat. 2015;2015:1-8.

15. Cooling MT, Hunter P. The CellML metadata framework 2.0 specification. J Integr Bioinform. 2015;12(2):260

16. Nickerson DP, Ladd D, Hussan JR, Safaei S, Suresh V, Hunter PJ, Bradley CP. Using CellML with OpenCMISS to simulate multi-scale physiology. Front Bioeng Biotechnol. 2014;2:79.

17. Yu T, Lloyd CM, Nickerson DP, Cooling MT, Miller AK, Garny A, Terkildsen JR, Lawson J, Britten RD, Hunter PJ, Nielsen PM. The physiome model repository 2. Bioinformatics. 2011;27(5):743-4.

18. Carson ER, Cobelli C. Modelling methodology for physiology and medicine. Acad Press Series Biomed Eng. 2001;xiv:421.

19. Garny A, Hunter PJ. OpenCOR: a modular and interoperable approach to computational biology. Front Physiol. 2015;6:26

20. Hunter PJ, Crampin EJ, Nielsen PM. Bioinformatics, multiscale modeling and the IUPS physiome project. Brief Bioinform. 2008;9(4):333-43.

21. Cohen MJ. Use of models in identification and prediction of physiology in critically ill surgical patients. Br J Surg 2012;99(4):487-93.

22. Vodovotz Y, Billiar TR. In silico modeling: methods and applications to trauma and sepsis. Crit Care Med. 2013:41(8):2008-14

23. Chase J, Shaw G, Wong X, Lotz T, Lin J, Hann C. Model-based glycaemic control in critical care-a review of the state of the possible. Biomed Signal Process Control. 2006;1(1):3-21.

24. Chase J, LeCompte A, Shaw G, Blakemore A, Wong J, Lin J, Hann C. A benchmark data set for model-based glycemic control in critical care. J Diabetes Sci Technol (JoDST). 2008;24(4):584-94. 
25. Chase JG, Le Compte AJ, Preiser JC, Shaw GM, Penning S, Desaive T. Physiological modeling, tight glycemic control, and the ICU clinician: what are models and how can they affect practice? Ann Intensive Care. 2011;1 (1):11.

26. Hovorka R, Chassin LJ, Wilinska ME. Virtual type 1 diabetic treated by CSII: model description. In: WC2003: 24-29 Aug 2003; Sydney, Australia; 2003.

27. Tawhai MH, Burrowes KS, Hoffman EA. Computational models of structure-function relationships in the pulmonary circulation and their validation. Exp Physiol. 2006;91(2):285-93.

28. Ben-Tal A. Simplified models for gas exchange in the human lungs. J Theor Biol. 2006;238(2):474-95.

29. Tawhai MH, Lin C-L. Image-based modeling of lung structure and function. J Magn Reson Imaging. 2010:32(6):1421-31.

30. Tawhai MH, Bates JHT. Multi-scale lung modeling. J Appl Physiol. 2011;110(5):1466-72.

31. Bradley C, Bowery A, Britten R, Budelmann V, Camara O, Christie R, Cookson A, Frangi AF, Gamage TB, HeidlaufT, Krittian S, Ladd D, Little C, Mithraratne K, Nash M, Nickerson D, Nielsen P, Nordbo O, Omholt S, Pashaei A, Paterson D, Rajagopal V, Reeve A, Rohrle O, Safaei S, Sebastian R, Steghofer M, Wu T, Yu T, Zhang H, Hunter P. OpenCMISS: a multi-physics \& multi-scale computational infrastructure for the VPH/Physiome project. Prog Biophys Mol Biol. 2011;107(1):32-47.

32. Hunter P, Chapman T, Coveney PV, de Bono B, Diaz V, Fenner J, Frangi AF, Harris P, Hose R, Kohl P, Lawford P, McCormack K, Mendes M, Omholt S, Quarteroni A, Shublaq N, Skar J, Stroetmann K, Tegner J, Thomas SR, Tollis I, Tsamardinos I, van Beek JH, Viceconti M. A vision and strategy for the virtual physiological human: 2012 update. Interface Focus. 2013;3(2):20130004.

33. Smith N, Waters S, Hunter P, Clayton R. The cardiac physiome: foundations and future prospects for mathematical modelling of the heart. Prog Biophys Mol Biol. 2011;104(1-3):1.

34. Pironet A, Desaive T, Kosta S, Lucas A, Paeme S, Collet A, Pretty CG, Kolh P, Dauby PC. A multi-scale cardiovascular system model can account for the load-dependence of the end-systolic pressure-volume relationship. Biomed Eng Online. 2013;12:8.

35. Keener JP, Sneyd J. Mathematical physiology. New York: Springer; 1998.

36. Wilinska ME, Chassin L, Hovorka R. In silico testing_impact on the progress of the closed loop insulin infusion for critically III patients project. J Diabetes Sci Technol. 2008;2(3):417-23.

37. Pielmeier U, Andreassen S, Nielsen BS, Chase JG, Haure P. A simulation model of insulin saturation and glucose balance for glycemic control in ICU patients. Comput Methods Program Biomed. 2010;97(3):211-22.

38. Tawhai MH, Hoffman EA, Lin C-L. The lung physiome: merging imaging-based measures with predictive computational models. Wiley Interdisciplin Rev. 2009;1 (1):61-72.

39. Barrett PH, Bell BM, Cobelli C, Golde H, Schumitzky A, Vicini P, Foster DM. SAAM II: simulation, analysis, and modeling software for tracer and pharmacokinetic studies. Metabolism. 1998;47(4):484-92.

40. Bergman RN, Ider YZ, Bowden CR, Cobelli C. Quantitative estimation of insulin sensitivity. Am J Physiol. 1979;236(6):E667-77.

41. Dalla Man C, Caumo A, Cobelli C. The oral glucose minimal model: estimation of insulin sensitivity from a meal test. IEEE Trans Biomed Eng. 2002;49(5):419-29.

42. Dalla Man C, Camilleri M, Cobelli C. A system model of oral glucose absorption: validation on gold standard data. IEEE Trans Biomed Eng. 2006;53(12 Pt 1):2472-8.

43. Man CD, Breton MD, Cobelli C. Physical activity into the meal glucose-insulin model of type 1 diabetes: in silico studies. J Diabetes Sci Technol (Online). 2009;3(1):56-67.

44. Pillonetto G, Caumo A, Sparacino G, Cobelli C. A new dynamic index of insulin sensitivity. IEEE Trans Biomed Eng. 2006;53(3):369-79.

45. Toffolo G, Cobelli C. The hot IVGTT two-compartment minimal model: an improved version. Am J Physiol Endocrinol Metab. 2003;284(2):E317-21.

46. Wilinska ME, Chassin LJ, Acerini CL, Allen JM, Dunger DB, Hovorka R. Simulation environment to evaluate closedloop insulin delivery systems in type 1 diabetes. J Diabetes Sci Technol (Online). 2010;4(1):132-44.

47. Callegari T, Caumo A, Cobelli C. Bayesian two-compartment and classic single-compartment minimal models: comparison on insulin modified IVGTT and effect of experiment reduction. IEEE Trans Biomed Eng. 2003;50(12):1301-9.

48. Hunter P, Coveney PV, de Bono B, Diaz V, Fenner J, Frangi AF, Harris P, Hose R, Kohl P, Lawford P, McCormack K, Mendes M, Omholt S, Quarteroni A, Skar J, Tegner J, Randall Thomas S, Tollis I, Tsamardinos I, van Beek JH, Viceconti M. A vision and strategy for the virtual physiological human in 2010 and beyond. Philos Transact A Math Phys Eng Sci. 1920;2010(368):2595-614.

49. Willmann S, Hohn K, Edginton A, Sevestre M, Solodenko J, Weiss W, Lippert J, Schmitt W. Development of a physiology-based whole-body population model for assessing the influence of individual variability on the pharmacokinetics of drugs. J Pharmacokinet Pharmacodyn. 2007;34(3):401-31.

50. Cutrone A, De Maria C, Vinci B, Vozzi F, Ahluwalia A, Vozzi G. A new library of HEMET model: insulin effects on hepatic metabolism. Comput Methods Programs Biomed. 2009;94(2):181-9.

51. Ramachandran D, Luo C, Ma TS, Clark JW Jr. Using a human cardiovascular-respiratory model to characterize cardiac tamponade and pulsus paradoxus. Theor Biol Med Model. 2009;6:15.

52. Tawhai MH, Nash MP, Hoffman EA. An imaging-based computational approach to model ventilation distribution and soft-tissue deformation in the ovine lung. Acad Radiol. 2006;13(1):113-20.

53. Hunter PJ, Nielsen PM, Smaill BH, LeGrice IJ, Hunter IW. An anatomical heart model with applications to myocardial activation and ventricular mechanics. Crit Rev Biomed Eng. 1992;20(5-6):403-26.

54. Hunter P, Smith N, Fernandez J, Tawhai M. Integration from proteins to organs: the IUPS physiome project. Mech Ageing Dev. 2005;126(1):187-92.

55. Safaei S, Bradley CP, Suresh V, Mithraratne K, Muller A, Ho H, Ladd D, Hellevik LR, Omholt SW, Chase JG, Muller LO, Watanabe SM, Blanco PJ, de Bono B, Hunter PJ. Roadmap for cardiovascular circulation model. J Physiol. 2016;594:6909-28 
56. Tawhai MH, Burrowes KS. Multi-scale models of the lung airways and vascular system. Integr Respir Control. 2008;605(5):190-4.

57. Hunter P. The virtual physiological human: the physiome project aims to develop reproducible, multiscale models for clinical practice. IEEE Pulse. 2016;7(4):36-42.

58. Viceconti M, Hunter P. The virtual physiological human: ten years after. Annu Rev Biomed Eng. 2016;18:103-23.

59. de Bono B, Safaei S, Grenon P, Nickerson DP, Alexander S, Helvensteijn M, Kok JN, Kokash N, Wu A, Yu T, Hunter P, Baldock RA. The open physiology workflow: modeling processes over physiology circuitboards of interoperable tissue units. Front Physiol. 2015;6:24.

60. Britten RD, Christie GR, Little C, Miller AK, Bradley C, Wu A, Yu T, Hunter P, Nielsen P. FieldML, a proposed open standard for the physiome project for mathematical model representation. Med Biol Eng Comput. 2013:51(11):1191-207.

61. Christie GR, Nielsen PM, Blackett SA, Bradley CP, Hunter PJ. FieldML: concepts and implementation. Philos Trans A Math Phys Eng Sci. 1895;2009(367):1869-84.

62. Gianni D, McKeever S, Yu T, Britten R, Delingette H, Frangi A, Hunter P, Smith N. Sharing and reusing cardiovascular anatomical models over the Web: a step towards the implementation of the virtual physiological human project. Philos Trans A Math Phys Eng Sci. 1921;2010(368):3039-56.

63. Garny A, Cooper J, Hunter PJ. Toward a VPH/Physiome ToolKit. Wiley Interdiscip Rev Syst Biol Med. 2010;2(2):134-47.

64. Garny A, Nickerson DP, Cooper J, Weber dos Santos R, Miller AK, McKeever S, Nielsen PM, Hunter PJ. CellML and associated tools and techniques. Philos Trans A Math Phys Eng Sci. 1878;2008(366):3017-43.

65. Bassingthwaighte J, Hunter P, Noble D. The cardiac physiome: perspectives for the future. Exp Physiol. 2009:94(5):597-605.

66. Hunter P, Nielsen P. A strategy for integrative computational physiology. Physiology (Bethesda). 2005;20:316-25.

67. Nickerson D, Atalag K, de Bono B, Geiger J, Goble C, Hollmann S, Lonien J, Muller W, Regierer B, Stanford NJ, Golebiewski M, Hunter P. The human physiome: how standards, software and innovative service infrastructures are providing the building blocks to make it achievable. Interface Focus. 2016;6(2):20150103.

68. Thomas S, Wolstencroft K, de Bono B, Hunter PJ. A physiome interoperability roadmap for personalized drug development. Interface Focus. 2016;6(2):20150094.

69. Dong Y, Chbat NW, Gupta A, Hadzikadic M, Gajic O. Systems modeling and simulation applications for critical care medicine. Ann Intensive Care. 2012;2(1):18.

70. Revie JA, Stevenson DJ, Chase JG, Hann CE, Lambermont BC, Ghuysen A, Kolh P, Shaw GM, Heldmann S, Desaive T. Validation of subject-specific cardiovascular system models from porcine measurements. Comput Methods Programs Biomed. 2013;109(2):197-210.

71. Pironet A, Desaive T, Geoffrey Chase J, Morimont P, Dauby PC. Model-based computation of total stressed blood volume from a preload reduction manoeuvre. Math Biosci. 2015;265:28-39.

72. Plank J, Blaha J, Cordingley J, Wilinska ME, Chassin LJ, Morgan C, Squire S, Haluzik M, Kremen J, Svacina S, Toller W, Plasnik A, Ellmerer M, Hovorka R, Pieber TR. Multicentric, randomized, controlled trial to evaluate blood glucose control by the model predictive control algorithm versus routine glucose management protocols in intensive care unit patients. Diabetes Care. 2006;29(2):271-6.

73. Blaha J, Hovorka R, Matias M, Kotulak T, Kremen J, Sloukova A, Svacina S, Haluzik M. Intensive insulin therapy in critically ill patients: comparison of standard and MPC protocols. Intensive Care Med. 2005;31 (S1):S203.

74. Blaha J, Kopecky P, Matias M, Hovorka R, Kunstyr J, Kotulak T, Lips M, Rubes D, Stritesky M, Lindner J, Semrad M, Haluzik M. Comparison of three protocols for tight glycemic control in cardiac surgery patients. Diabetes Care. 2009:32(5):757-61.

75. Van Herpe T, De Moor B, Van den Berghe G. Towards closed-loop glycaemic control. Best Pract Res. 2009;23(1):69-80.

76. Van Herpe T, Mesotten D, Wouters PJ, Herbots J, Voets E, Buyens J, De Moor B, Van den Berghe G. LOGIC-insulin algorithm-guided versus nurse-directed blood glucose control during critical illness: the LOGIC-1 single-center randomized, controlled clinical trial. Diabetes Care. 2013;36(2):189-94.

77. Szlavecz A, Chiew Y, Redmond D, Beatson A, Glassenbury D, Corbett S, Major V, Pretty C, Shaw G, Benyo B, Desaive T, Chase J. The Clinical Utilisation of Respiratory Elastance Software (CURE Soft): a bedside software for real-time respiratory mechanics monitoring and mechanical ventilation management. BioMed Eng Online. 2014;13(1):140.

78. Rees SE, Kjærgaard S, Thorgaard P, Malczynski J, Toft E, Andreassen S. The Automatic Lung Parameter Estimator (ALPE) System: non-invasive estimation of pulmonary gas exchange parameters in 10-15 minutes. J Clin Monit Comput. 2002;17(1):43-52.

79. Rees S, Allerød C, Murley D, Zhao Y, Smith B, Kjærgaard S, Thorgaard P, Andreassen S. Using physiological models and decision theory for selecting appropriate ventilator settings. J Clin Monit Comput. 2006;20(6):421-9.

80. Rees SE. The Intelligent Ventilator (INVENT) project: the role of mathematical models in translating physiological knowledge into clinical practice. Comput Methods Programs Biomed. 2011;104(Supplement 1(0)):S1-29.

81. Morris AH, Orme J Jr, Truwit JD, Steingrub J, Grissom C, Lee KH, Li GL, Thompson BT, Brower R, Tidswell M, Bernard GR, Sorenson D, Sward K, Zheng H, Schoenfeld D, Warner H. A replicable method for blood glucose control in critically III patients. Crit Care Med. 2008;36(6):1787-95.

82. Le Compte AJ, Lynn AM, Lin J, Pretty CG, Shaw GM, Chase JG. Pilot study of a model-based approach to blood glucose control in very-low-birthweight neonates. BMC Pediatr. 2012;12:117.

83. Cochran S, Miller E, Dunn K. EndoTool software for tight glucose control for critically ill patients. Crit Care Med. 2006;34(Suppl 2):A68

84. Pielmeier U, Andreassen S, Juliussen B, Chase JG, Nielsen BS, Haure P. The Glucosafe system for tight glycemic control in critical care: a pilot evaluation study. J Crit Care. 2010;25(1):97-104.

85. Pielmeier U, Rousing ML, Andreassen S, Nielsen BS, Haure P. Decision support for optimized blood glucose control and nutrition in a neurotrauma intensive care unit: preliminary results of clinical advice and prediction accuracy of the Glucosafe system. J Clin Monit Comput. 2012;26(4):319-28. 
86. Desaive T, Lambermont B, Janssen N, Ghuysen A, Kolh P, Morimont P, Dauby PC, Starfinger C, Shaw GM, Chase JG. Assessment of ventricular contractility and ventricular-arterial coupling with a model-based sensor. Comput Methods Programs Biomed. 2013;109(2):182-9.

87. Larraza S, Dey N, Karbing DS, Jensen JB, Nygaard M, Winding R, Rees SE. A mathematical model approach quantifying patients' response to changes in mechanical ventilation: evaluation in pressure support. J Crit Care. 2015;37:341-9.

88. Lin J, Parente JD, Chase JG, Shaw GM, Blakemore AJ, LeCompte AJ, Pretty C, Razak NN, Lee DS, Hann CE. Development of a model-based clinical sepsis biomarker for critically ill patients. Comput Methods Programs Biomed. 2011:102(2):149-55.

89. Evans A, Shaw GM, Le Compte A, Tan CS, Ward L, Steel J, Pretty CG, Pfeifer L, Penning S, Suhaimi F. Pilot proof of concept clinical trials of Stochastic Targeted (STAR) glycemic control. Ann Intensive Care. 2011;1 (1):38.

90. Fisk L, Lecompte A, Penning S, Desaive T, Shaw G, Chase G. STAR development and protocol comparison. IEEE Trans Biomed Eng. 2012;59(12):3357-64.

91. Vincent JL, Hall JB, Slutsky AS. Ten big mistakes in intensive care medicine. Intensive Care Med. 2015;41 (3):505-7.

92. Vincent JL. Improved survival in critically ill patients: are large RCTs more useful than personalized medicine? No. Intensive Care Med. 2016;42(11):1778-80.

93. Vincent JL. We should abandon randomized controlled trials in the intensive care unit. Crit Care Med. 2010;38(10 Suppl):S534-8.

94. Grasselli G, Gattinoni L, Kavanagh B, Latini R, Laupacis A, Lemaire F, Pesenti A, Suter P, Slutsky A, Tognoni G. Feasibility, limits and problems of clinical studies in Intensive Care Unit. Minerva Anestesiol. 2007;73(11):595-601.

95. De Simone J. Beyond 'faith-based medicine' and EBM. J Eval Clin Pract. 2006;12(4):438-44.

96. Shaw GM, Chase JG. Why evidence based medicine may be bad for you and your patients. In: Nayyar $\vee$, editor. Critical Care Update 2006. New Dehli: Jaypee Medical Publishers; 2007. p. 9-20.

97. Ospina-Tascon GA, Buchele GL, Vincent JL. Multicenter, randomized, controlled trials evaluating mortality in intensive care: doomed to fail? Crit Care Med. 2008;36(4):1311-22.

98. Celermajer DS. Evidence-based medicine: how good is the evidence? Med J Aust. 2001;174(6):293-5.

99. Kovatchev BP, Breton M, Man CD, Cobelli C. In silico preclinical trials: a proof of concept in closed-loop control of type 1 diabetes. J Diabetes Sci Technol (Online). 2009;3(1):44-55.

100. Viceconti M, Cobelli C, Haddad T, Himes A, Kovatchev B, Palmer M. In silico assessment of biomedical products: the conundrum of rare but not so rare events in two case studies. Proc Inst Mech Eng H. 2017;231 (5):455-66.

101. Wilinska ME, Chassin L, Hovorka R. Automated glucose control in the ICU: effect of nutritional protocol and measurement error. Conf Proc IEEE Eng Med Biol Soc. 2006;1:67-70.

102. Van Herpe T, De Moor B, Van den Berghe G, Mesotten D. Modeling of effect of glucose sensor errors on insulin dosage and glucose bolus computed by LOGIC-insulin. Clin Chem. 2014;60:1510-8.

103. Pretty CG, Signal M, Fisk L, Penning S, Le Compte A, Shaw GM, Desaive T, Chase JG. Impact of sensor and measurement timing errors on model-based insulin sensitivity. Comput Methods Programs Biomed. 2014;114(3):e79-86.

104. Signal M, Pretty CG, Chase JG, Le Compte A, Shaw GM. Continuous glucose monitors and the burden of tight glycemic control in critical care: can they cure the time cost? J Diabetes Sci Technol (Online). 2010;4(3):625-35.

105. Krinsley JS, Bruns DE, Boyd JC. The impact of measurement frequency on the domains of glycemic control in the critically ill—a Monte Carlo simulation. J Diabetes Sci Technol (Online). 2015;9(2):237-45.

106. Chase J, Andreassen S, Jensen K, Shaw G. The impact of human factors on clinical protocol performance-a proposed assessment framework and case examples. J Diabetes Sci Technol (Online). 2008;2(3):409-16.

107. Bion JF, Abrusci T, Hibbert P. Human factors in the management of the critically ill patient. Br J Anaesth. 2010;105(1):26-33

108. Anderson J, Gosbee LL, Bessesen M, Williams L. Using human factors engineering to improve the effectiveness of infection prevention and control. Crit Care Med. 2010;38(8 Suppl):S269-81.

109. Bellagamba G, Gionta G, Senergue J, Beque C, Lehucher-Michel MP. Organizational factors impacting job strain and mental quality of life in emergency and critical care units. Int J Occup Med Environ Health. 2015;28(2):357-67.

110. Dyson M. Modern critical care unit design. Nursing implications in modern critical care unit design: bed area ergonomics. Nurs Crit Care. 1996;1(4):194-7.

111. Morineau T, Chapelain P, Quinio P. Task management skills and their deficiencies during care delivery in simulated medical emergency situation: a classification. Intensive Crit Care Nurs. 2016;34:34-42.

112. Hudachek SF, Gustafson DL. Customized in silico population mimics actual population in docetaxel population pharmacokinetic analysis. J Pharm Sci. 2011;100(3):1156-66.

113. Fink M, Niederer SA, Cherry EM, Fenton FH, Koivumaki JT, Seemann G, Thul R, Zhang H, Sachse FB, Beard D, Crampin EJ, Smith NP. Cardiac cell modelling: observations from the heart of the cardiac physiome project. Prog Biophys Mol Biol. 2011;104(1-3):2-21.

114. Ljung L, Glad T. On global identifiability for arbitrary model parametrizations. Automatica. 1994;30(2):265-76.

115. Wongvanich N, Hann CE, Sirisena HR. Robust global identifiability theory using potentials_application to compartmental models. Math Biosci. 2015;262:182-97.

116. Chase JG, Suhaimi F, Penning S, Preiser JC, Le Compte AJ, Lin J, Pretty CG, Shaw GM, Moorhead KT, Desaive T. Validation of a model-based virtual trials method for tight glycemic control in intensive care. Biomed Eng Online. 2010;9:84

117. Chase JG, Le Compte AJ, Suhaimi F, Shaw GM, Lynn A, Lin J, Pretty CG, Razak N, Parente JD, Hann CE. Tight glycemic control in critical care-The leading role of insulin sensitivity and patient variability: a review and model-based analysis. Comput Methods Programs Biomed. 2011;102(2):156-71.

118. Hann CE, Chase JG, Lin J, Lotz T, Doran CV, Shaw GM. Integral-based parameter identification for long-term dynamic verification of a glucose-insulin system model. Comput Methods Programs Biomed. 2005;77(3):259-70.

119. Lin J, Lee D, Chase JG, Shaw GM, Hann CE, Lotz T, Wong J. Stochastic modelling of insulin sensitivity variability in critical care. Biomed Signal Process Control. 2006;1(3):229-42. 
120. Lin J, Lee D, Chase JG, Shaw GM, Le Compte A, Lotz T, Wong J, Lonergan T, Hann CE. Stochastic modelling of insulin sensitivity and adaptive glycemic control for critical care. Comput Methods Programs Biomed. 2008;89(2):141-52.

121. Lin J, Razak NN, Pretty CG, Le Compte A, Docherty P, Parente JD, Shaw GM, Hann CE, Geoffrey Chase J. A physiological intensive control insulin-nutrition-glucose (ICING) model validated in critically ill patients. Comput Methods Programs Biomed. 2011;102(2):192-205.

122. Hovorka R, Shojaee-Moradie F, Carroll PV, Chassin LJ, Gowrie IJ, Jackson NC, Tudor RS, Umpleby AM, Jones RH. Partitioning glucose distribution/transport, disposal, and endogenous production during IVGTT. Am J Physiol Endocrinol Metab. 2002;282(5):E992-1007.

123. Hovorka R, Chassin LJ, Ellmerer M, Plank J, Wilinska ME. A simulation model of glucose regulation in the critically ill. Physiol Meas. 2008;29(8):959-78.

124. Langouche L, Vander Perre S, Wouters PJ, D'Hoore A, Hansen TK, Van den Berghe G. Effect of intensive insulin therapy on insulin sensitivity in the critically ill. J Clin Endocrinol Metab. 2007;92(10):3890-7.

125. Mari A, Pacini G, Brazzale AR, Ahren B. Comparative evaluation of simple insulin sensitivity methods based on the oral glucose tolerance test. Diabetologia. 2005;48(4):748-51.

126. Le Compte A, Chase J, Lynn A, Hann C, Shaw G, Wong X, Lin J. Blood Glucose Controller for Neonatal Intensive Care: virtual trials development and 1st clinical trials. J Diabetes Sci Technol (JoDST). 2009;3(5):1066-81.

127. Docherty PD, Chase JG, Morenga L, Lotz TF, Berkeley J, Shaw G, McAuley K, Mann J. A spectrum of dynamic insulin sensitivity test protocols. J Diabetes Sci Technol. 2011;5(6):1499.

128. Blaha J, Barteczko-Grajek B, Berezowicz P, Charvat J, Chvojka J, Grau T, Holmgren J, Jaschinski U, Kopecky P, Manak J, Moehl M, Paddle J, Pasculli M, Petersson J, Petros S, Radrizzani D, Singh V, Starkopf J. Space GlucoseControl system for blood glucose control in intensive care patients_a European multicentre observational study. BMC Anesthesiol. 2016;16:8.

129. Cobelli C, Pacini G, Toffolo G, Sacca L. Estimation of insulin sensitivity and glucose clearance from minimal model: new insights from labeled IVGTT. Am J Physiol. 1986;250(5 Pt 1):E591-8.

130. Dalla Man C, Yarasheski KE, Caumo A, Robertson H, Toffolo G, Polonsky KS, Cobelli C. Insulin sensitivity by oral glucose minimal models: validation against clamp. Am J Physiol Endocrinol Metab. 2005;289(6):E954-9.

131. Sah Pri A, Chase JG, Pretty CG, Shaw GM, Preiser JC, Vincent JL, Oddo M, Taccone FS, Penning S, Desaive T. Evolution of insulin sensitivity and its variability in out-of-hospital cardiac arrest (OHCA) patients treated with hypothermia. Crit Care. 2014;18(5):586.

132. Pretty C, Chase JG, Lin J, Shaw GM, Le Compte A, Razak N, Parente JD. Impact of glucocorticoids on insulin resistance in the critically ill. Comput Methods Programs Biomed. 2011;102(2):172-80.

133. Pretty CG, Le Compte AJ, Chase JG, Shaw GM, Preiser JC, Penning S, Desaive T. Variability of insulin sensitivity during the first 4 days of critical illness: implications for tight glycemic control. Ann Intensive Care. 2012;2(1):17.

134. Jamaludin UK, Docherty PD, Geoffrey Chase J, Shaw GM. Impact of haemodialysis on insulin kinetics of acute kidney injury patients in critical care. J Med Biol Eng. 2015;35(1):125-33.

135. Le Compte AJ, Pretty CG, Lin J, Shaw GM, Lynn A, Chase JG. Impact of variation in patient response on modelbased control of glycaemia in critically ill patients. Comput Methods Programs Biomed. 2011;109:211-9.

136. Thomas F, Pretty CG, Fisk L, Shaw GM, Chase JG, Desaive T. Reducing the impact of insulin sensitivity variability on glycaemic outcomes using separate stochastic models within the STAR glycaemic protocol. Biomed Eng Online. 2014;13:43.

137. Mowery NT, Gunter OL, Dossett LA, Dortch MJ, Morris JA Jr, May AK, Diaz JJ Jr. Failure to achieve euglycemia despite aggressive insulin control signals abnormal physiologic response to trauma. J Crit Care. 2011;26(3):295-302

138. Cueni-Villoz N, Devigili A, Delodder F, Cianferoni S, Feihl F, Rossetti AO, Eggimann P, Vincent JL, Taccone FS, Oddo M. Increased blood glucose variability during therapeutic hypothermia and outcome after cardiac arrest. Crit Care Med. 2011;39(10):2225-31.

139. Ferenci T, Benyo B, Kovacs L, Fisk L, Shaw GM, Chase JG. Daily evolution of insulin sensitivity variability with respect to diagnosis in the critically ill. PLoS ONE. 2013;8(2):e57119.

140. Koch A, Gressner OA, Sanson E, Tacke F, Trautwein C. Serum resistin levels in critically ill patients are associated with inflammation, organ dysfunction and metabolism and may predict survival of non-septic patients. Crit Care. 2009;13(3):R95.

141. Laviano A, Aghilone F, Colagiovanni D, Fiandra F, Giambarresi R, Tordiglione P, Molfino A, Muscaritoli M, Rosa G, Rossi Fanelli F. Metabolic and clinical effects of the supplementation of a functional mixture of amino acids in cerebral hemorrhage. Neurocrit Care. 2011;14(1):44-9.

142. Chiew YS, Pretty C, Docherty PD, Lambermont B, Shaw GM, Desaive T, Chase JG. Time-varying respiratory system elastance: a physiological model for patients who are spontaneously breathing. PLOS ONE. 2015;10(1):e0114847.

143. van Drunen E, Chiew YS, Chase J, Shaw G, Lambermont B, Janssen N, Damanhuri N, Desaive T. Expiratory modelbased method to monitor ARDS disease state. BioMedical Eng OnLine. 2013;12(1):57.

144. van Drunen E, Chiew YS, Pretty C, Shaw G, Lambermont B, Janssen N, Chase J, Desaive T. Visualisation of timevarying respiratory system elastance in experimental ARDS animal models. BMC Pulm Med. 2014;14(1):33.

145. Bates JHT. The linear single-compartment model lung mechanics. Cambridge: Cambridge University Press; 2009 .

146. Redmond D, Chiew YS, van Drunen E, Shaw GM, Chase JG. A minimal algorithm for a minimal recruitment modelmodel estimation of alveoli opening pressure of an acute respiratory distress syndrome (ARDS) lung. Biomed Signal Process Control. 2014;14:1-8.

147. Rees SE, Andreassen S, Freundlich M, Morgan C, Carson ER, Thorgaard P. Selecting ventilator settings using INVENT, a system including physiological models and penalty functions. In: Proceedings of the joint conference of European societies of artificial intelligence in medicine and medical decision making workshop, computers in anesthesia and intensive care. Aalborg, Denmark; 1999. 
148. Carvalho AR, Bergamini BC, Carvalho NS, Cagido VR, Neto AC, Jandre FC, Zin WA, Giannella-Neto A. Volume-independent elastance: a useful parameter for open-lung positive end-expiratory pressure adjustment. Anesthesia Analgesia. 2013;116(3):627-33.

149. Stenqvist $\mathrm{O}$, Grivans $\mathrm{C}$, Andersson B, Lundin S: Lung elastance and transpulmonary pressure can be determined without using oesophageal pressure measurements. Acta Anaesthesiologica Scandinavica 2012:n/a-n/a.

150. Stenqvist O, Grivans C, Andersson B, Lundin S. Lung elastance and transpulmonary pressure can be determined without using oesophageal pressure measurements. Acta Anaesthesiol Scand. 2012;56:738.

151. Sundaresan A, Chase J, Shaw G, Chiew YS, Desaive T. Model-based optimal PEEP in mechanically ventilated ARDS patients in the Intensive Care Unit. BioMedical Eng OnLine. 2011;10(1):64.

152. Chiew YS, Chase JG, Shaw GM, Sundaresan A, Desaive T. Model-based PEEP optimisation in mechanical ventilation. Biomed Eng Online. 2011:10:111

153. Amato MBP, Meade MO, Slutsky AS, Brochard L, Costa ELV, Schoenfeld DA, Stewart TE, Briel M, Talmor D, Mercat A, Richard JCM, Carvalho CRR, Brower RG. Driving pressure and survival in the acute respiratory distress syndrome. N Engl J Med. 2015;372(8):747-55.

154. Carvalho A, Jandre F, Pino A, Bozza F, Salluh J, Rodrigues R, Soares J, Giannella-Neto A. Effects of descending positive end-expiratory pressure on lung mechanics and aeration in healthy anaesthetized piglets. Crit Care. 2006;10(4):R122.

155. Carvalho A, Jandre F, Pino A, Bozza F, Salluh J, Rodrigues R, Ascoli F, Giannella-Neto A. Positive end-expiratory pressure at minimal respiratory elastance represents the best compromise between mechanical stress and lung aeration in oleic acid induced lung injury. Crit Care. 2007:11(4):R86.

156. Carvalho A, Spieth P, Pelosi P, Vidal Melo M, Koch T, Jandre F, Giannella-Neto A, de Abreu M. Ability of dynamic airway pressure curve profile and elastance for positive end-expiratory pressure titration. Intensive Care Med. 2008;34(12):2291-9.

157. Suarez-Sipmann F, Bohm SH, Tusman G, Pesch T, Thamm O, Reissmann H, Reske A, Magnusson A, Hedenstierna G. Use of dynamic compliance for open lung positive end-expiratory pressure titration in an experimental study. Crit Care Med. 2007;35:214-21.

158. Lambermont B, Ghuysen A, Janssen N, Morimont P, Hartstein G, Gerard P, D'Orio V. Comparison of functional residual capacity and static compliance of the respiratory system during a positive end-expiratory pressure (PEEP) ramp procedure in an experimental model of acute respiratory distress syndrome. Crit Care. 2008;12(4):R91.

159. Camilo LM, Ávila MB, Cruz LFS, Ribeiro GCM, Spieth PM, Reske AA, Amato M, Giannella-Neto A, Zin WA, Carvalho AR. Positive end-expiratory pressure and variable ventilation in lung-healthy rats under general anesthesia. PLoS ONE. 2014;9(11):e110817.

160. Pintado M-C, de Pablo R, Trascasa M, Milicua J-M, Rogero S, Daguerre M, Cambronero J-A, Arribas I, SánchezGarcía M. Individualized PEEP setting in subjects with ARDS: a randomized controlled pilot study. Respir Care. 2013;58(9):1416-23.

161. Kamoi S, Pretty C, Docherty P, Squire D, Revie J, Chiew YS, Desaive T, Shaw GM, Chase JG. Continuous stroke volume estimation from aortic pressure using zero dimensional cardiovascular model: proof of concept study from porcine experiments. PLoS ONE. 2014;9(7):e102476.

162. Wujtewicz M. Fluid use in adult intensive care. Anaesthesiol Intensive Ther. 2012;44(2):92-5.

163. Maas JJ, Pinsky MR, Aarts LP, Jansen JR. Bedside assessment of total systemic vascular compliance, stressed volume, and cardiac function curves in intensive care unit patients. Anesth Analg. 2012;115(4):880-7.

164. Jansen JR, Maas JJ, Pinsky MR. Bedside assessment of mean systemic filling pressure. Curr Opin Crit Care. 2010;16(3):231-6.

165. Maas JJ, Geerts BF, van den Berg PC, Pinsky MR, Jansen JR. Assessment of venous return curve and mean systemic filling pressure in postoperative cardiac surgery patients. Crit Care Med. 2009;37(3):912-8.

166. Nouira S, Elatrous S, Dimassi S, Besbes L, Boukef R, Mohamed B, Abroug F. Effects of norepinephrine on static and dynamic preload indicators in experimental hemorrhagic shock. Crit Care Med. 2005;33(10):2339-43.

167. Cecconi M, De Backer D, Antonelli M, Beale R, Bakker J, Hofer C, Jaeschke R, Mebazaa A, Pinsky MR, Teboul JL, Vincent JL, Rhodes A. Consensus on circulatory shock and hemodynamic monitoring. Task force of the European Society of Intensive Care Medicine. Intensive Care Med. 2014;40(12):1795-815.

168. Cecconi M, Rhodes A. Validation of continuous cardiac output technologies: consensus still awaited. Crit Care. 2009;13(3):159.

169. Horster S, Stemmler HJ, Strecker N, Brettner F, Hausmann A, Cnossen J, Parhofer KG, Nickel T, Geiger S. Cardiac output measurements in septic patients: comparing the accuracy of USCOM to PiCCO. Crit Care Res Pract. 2012;2012:270631.

170. Huber W, Koenig J, Mair S, Schuster T, Saugel B, Eyer F, Phillip V, Schultheiss C, Thies P, Mayr U, Einwachter H, Treiber M, Hoellthaler J, Schmid RM. Predictors of the accuracy of pulse-contour cardiac index and suggestion of a calibration-index: a prospective evaluation and validation study. BMC Anesthesiol. 2015;15:45.

171. Litton E, Morgan M. The PiCCO monitor: a review. Anaesth Intensive Care. 2012;40(3):393-409.

172. Sakka SG, Kozieras J, Thuemer O, van Hout N. Measurement of cardiac output: a comparison between transpulmonary thermodilution and uncalibrated pulse contour analysis. Br J Anaesth. 2007;99(3):337-42.

173. Siranovic M, Kovac J, Gopcevic A, Kelecic M, Vucic M, Kovac N, Rode B. Constant cardiac output monitoring using the PiCCO and LiDCO methods versus PAK in septic patients: when to do calibration? Acta Clin Croat. 2011;50(2):267-72.

174. Rudge A, Wake G, Dove R, Starfinger C, Greenfield K, Shaw G, Lee D, Lam Z, Chase J. Rethinking sedation and agitation management in critical illness. Critical Care Resuscitation. 2003;5(3):198.

175. Rudge AD, Chase JG, Shaw GM, Lee D. Physiological modelling of agitation-sedation dynamics. Med Eng Phys. 2006;28(1):49-59.

176. Rudge A, Chase J, Shaw G, Lee D. Physiological modelling of agitation-sedation dynamics including endogenous agitation reduction. Med Eng Phys. 2006;28(7):629-38. 
177. Docherty PD, Chase JG, Lotz TF, Desaive T. A graphical method for practical and informative identifiability analyses of physiological models: a case study of insulin kinetics and sensitivity. Biomed Eng Online. 2011;10(1):1-20.

178. Audoly S, D'Angio L, Saccomani MP, Cobelli C. Global identifiability of linear compartmental models-a computer algebra algorithm. IEEE Trans Biomed Eng. 1998;45(1):36-47.

179. Audoly S, Bellu G, D'Angio L, Saccomani MP, Cobelli C. Global identifiability of nonlinear models of biological systems. IEEE Trans Biomed Eng. 2001;48(1):55-65.

180. Cobelli C, Carson ER, Finkelstein L, Leaning MS. Validation of simple and complex models in physiology and medicine. Am J Physiol. 1984;246(2 Pt 2):R259-66.

181. Pillonetto G, Sparacino G, Cobelli C. Numerical non-identifiability regions of the minimal model of glucose kinetics: superiority of Bayesian estimation. Math Biosci. 2003;184(1):53-67.

182. Schranz C, Docherty PD, Chiew YS, Chase JG, Moller K. Structural identifiability and practical applicability of an alveolar recruitment model for ARDS patients. IEEE Trans Biomed Eng. 2012;59(12):3396-404.

183. Chapman MJ, Godfrey KR, Chappell MJ, Evans ND. Structural identifiability for a class of non-linear compartmental systems using linear/non-linear splitting and symbolic computation. Math Biosci. 2003;183(1):1-14.

184. Lillacci G, Khammash M. Parameter estimation and model selection in computational biology. PLoS Comput Biol. 2010;6(3):e1000696

185. Hann CE, Revie J, Stevenson D, Heldmann S, Desaive T, Froissart CB, Lambermont B, Ghuysen A, Kolh P, Shaw GM, Chase JG. Patient specific identification of the cardiac driver function in a cardiovascular system model. Comput Methods Programs Biomed. 2011;101(2):201-7.

186. Burnham KP, Anderson DR. Multimodel inference-understanding AIC and BIC in model selection. Sociol Method Res. 2004;33(2):261-304.

187. Wagenmakers EJ. Model selection and multimodel inference: a practical information-theoretic approach. J Math Psychol. 2003;47(5-6):580-6.

188. Villaverde AF, Ross J, Banga JR. Reverse engineering cellular networks with information theoretic methods. Cells. 2013;2(2):306-29.

189. Villaverde AF, Banga JR. Reverse engineering and identification in systems biology: strategies, perspectives and challenges. J R Soc Interface. 2014;11(91):20130505.

190. Bellu G, Saccomani MP, Audoly S, D'Angio L. DAISY: a new software tool to test global identifiability of biological and physiological systems. Comput Methods Programs Biomed. 2007;88(1):52-61.

191. Tawhai M, Chase JG. Breathing easier: model-based decision support for respiratory care looks beyond tomorrow. IEEE Pulse. 2015:6(5):10-5.

192. Kretschmer J, Schranz C, Knobel C, Wingender J, Koch E, Moller K. Efficient computation of interacting model systems. J Biomed Inform. 2013;46(3):401-9.

193. Kretschmer J, Wahl A, Moller K. Dynamically generated models for medical decision support systems. Comput Biol Med. 2011;41(10):899-907.

194. Kretschmer J, Haunsberger T, Drost E, Koch E, Moller K. Simulating physiological interactions in a hybrid system of mathematical models. J Clin Monit Comput. 2014;28(6):513-23.

195. Lotz TF, Chase JG, MCAuley KA, Lee DS, Lin J, Hann CE, Mann JI. Transient and steady-state euglycemic clamp validation of a model for glycemic control and insulin sensitivity testing. Diabetes Technol Ther. 2006;8(3):338-46.

196. McAuley KA, Berkeley JE, Docherty PD, LotzTF, Te Morenga LA, Shaw GM, Williams SM, Chase JG, Mann JI. The dynamic insulin sensitivity and secretion test-a novel measure of insulin sensitivity. Metabolism. 2011;60:1748-56.

197. Chiew YS, Chase JG, Shaw G, Sundaresan A, Desaive T. Model-based PEEP optimisation in mechanical ventilation. BioMedical Eng OnLine. 2011;10(1):111.

198. Chiew Y, Pretty C, Shaw G, Chiew Y, Lambermont B, Desaive T, Chase J. Feasibility of titrating PEEP to minimum elastance for mechanically ventilated patients. Pilot Feasibility Stud. 2015;1(1):9.

199. Langdon R, Docherty PD, Chiew YS, Chase JG. Extrapolation of a non-linear autoregressive model of pulmonary mechanics. Math Biosci. 2016;284:32-9.

200. Bates JHT. Lung mechanics: an inverse modeling approach. New York: Cambridge University Press; 2009.

201. Wang JJ, O'Brien AB, Shrive NG, Parker KH, Tyberg JV. Time-domain representation of ventricular-arterial coupling as a windkessel and wave system. Am J Physiol Heart Circul Physiol. 2003;284(4):H1358-68.

202. Wesseling KH, Jansen JR, Settels JJ, Schreuder JJ. Computation of aortic flow from pressure in humans using a nonlinear, three-element model. J Appl Physiol (1985). 1993;74(5):2566-73.

203. Magder S. Understanding central venous pressure: not a preload index? Curr Opin Crit Care. 2015;21 (5):369-75.

204. Monnet X, Teboul JL. Volume responsiveness. Curr Opin Crit Care. 2007;13(5):549-53.

205. Lira A, Pinsky MR. Choices in fluid type and volume during resuscitation: impact on patient outcomes. Ann Intensive Care. 2014;4:38

206. Marik PE. Techniques for assessment of intravascular volume in critically ill patients. J Intensive Care Med. 2009;24(5):329-37.

207. Scott MC, Mallemat H. Assessing volume status. Emerg Med Clin North Am. 2014;32(4):811-22.

208. Bracht H, Calzia E, Georgieff M, Singer J, Radermacher P, Russell JA. Inotropes and vasopressors: more than haemodynamics! Br J Pharmacol. 2012;165(7):2009-11.

209. Hollenberg SM. Inotrope and vasopressor therapy of septic shock. Crit Care Clin. 2009;25(4):781-802.

210. Swan A, Hunter P, Tawhai M. Pulmonary gas exchange in anatomically-based models of the lung. Adv Exp Med Biol. 2008;605:184-9.

211. Karbing DS, Thomsen LP, Moesgaard J, Andreassen S, Toft E, Thorgaard P, Rees SE. Model-based measurement of gas exchange in healthy subjects using ALPE essential-influence of age, posture and gender. Conf Proc IEEE Eng Med Biol Soc. 2013;2013:2441-4.

212. Docherty PD, Chase JG, David T. Characterisation of the iterative integral parameter identification method. Med Biol Eng Compu. 2012;50(2):127-34.

213. Ljung L, Söderström T. Theory and practice of recursive identification. Cambridge, Mass: MIT Press; 1983.

214. Ljung L. System identification: theory for the user. 2nd ed. Upper Saddle River: Prentice Hall PTR; 1999. 
215. Norton JP. An introduction to identification. Dover ed. Mineola: Dover Publications; 2009.

216. Godsland IF, Agbaje OF, Hovorka R. Evaluation of nonlinear regression approaches to estimation of insulin sensitivity by the minimal model with reference to Bayesian hierarchical analysis. Am J Physiol Endocrinol Metab. 2006;291(1):E167-74.

217. Denti P, Bertoldo A, Vicini P, Cobelli C. Identification of IVGTT minimal glucose model by nonlinear mixed-effects approaches. Conf Proc IEEE Eng Med Biol Soc. 2006;1:5049-52.

218. Thomaseth K, Cobelli C. Generalized sensitivity functions in physiological system identification. Ann Biomed Eng. 1999;27(5):607-16.

219. Bates JHT. Pulmonary mechanics: a system identification perspective. In: Engineering in medicine and biology society, 2009 EMBC 2009 annual international conference of the IEEE: 3-6 Sept. 2009; 2009: 170-2.

220. Cobelli C, Caumo A, Omenetto M. Minimal model SG overestimation and SI underestimation: improved accuracy by a Bayesian two-compartment model. Am J Physiol. 1999;277(3 Pt 1):E481-8.

221. Magni P, Sparacino G, Bellazzi R, Toffolo GM, Cobelli C. Insulin minimal model indexes and secretion: proper handling of uncertainty by a Bayesian approach. Ann Biomed Eng. 2004;32(7):1027-37.

222. Magni P, Sparacino G, Bellazzi R, Cobelli C. Reduced sampling schedule for the glucose minimal model: importance of Bayesian estimation. Am J Physiol Endocrinol Metab. 2006;290(1):E177-84.

223. Krinsley JS, Preiser JC. Time in blood glucose range 70 to $140 \mathrm{mg} / \mathrm{dl}>80 \%$ is strongly associated with increased survival in non-diabetic critically ill adults. Crit Care. 2015;19:179.

224. Egi M, Bellomo R, Stachowski E, French CJ, Hart GK, Taori G, Hegarty C, Bailey M. Hypoglycemia and outcome in critically ill patients. Mayo Clin Proc. 2010;85(3):217-24.

225. St-Arnaud C, Ethier JF, Hamielec C, Bersten A, Guyatt G, Meade M, Zhou Q, Leclair MA, Patel A, Lamontagne F. Prescribed targets for titration of vasopressors in septic shock: a retrospective cohort study. CMAJ Open. 2013;1(4):E127-33.

226. Uyttendaele V, Dickson JL, Shaw GM, Desaive T, Chase JG. Untangling glycaemia and mortality in critical care. Crit Care. 2017;21(1):152.

227. Penning S, Chase JG, Preiser JC, Pretty CG, Signal M, Melot C, Desaive T. Does the achievement of an intermediate glycemic target reduce organ failure and mortality? A post hoc analysis of the Glucontrol trial. J Crit Care. 2014;29(3):374-9.

228. Penning S, Pretty C, Preiser JC, Shaw GM, Desaive T, Chase JG. Glucose control positively influences patient outcome: a retrospective study. J Crit Care. 2015;30(3):455-9.

229. Signal M, Le Compte A, Shaw GM, Chase JG. Glycemic levels in critically ill patients: are normoglycemia and low variability associated with improved outcomes? J Diabetes Sci Technol (Online). 2012;6(5):1030-7.

230. Finfer S, Liu B, Chittock DR, Norton R, Myburgh JA, McArthur C, Mitchell I, Foster D, Dhingra V, Henderson WR, Ronco JJ, Bellomo R, Cook D, McDonald E, Dodek P, Hebert PC, Heyland DK, Robinson BG. Hypoglycemia and risk of death in critically ill patients. N Engl J Med. 2012;367(12):1108-18.

231. Bagshaw SM, Bellomo R, Jacka MJ, Egi M, Hart GK, George C. The impact of early hypoglycemia and blood glucose variability on outcome in critical illness. Crit Care. 2009;13(3):R91.

232. Egi M, Bellomo R, Stachowski E, French CJ, Hart G. Variability of blood glucose concentration and short-term mortality in critically ill patients. Anesthesiology. 2006;105(2):244-52.

233. Egi M, Bellomo R. Reducing glycemic variability in intensive care unit patients: a new therapeutic target? J Diabetes Sci Technol (Online). 2009;3(6):1302-8.

234. Aragon D. Evaluation of nursing work effort and perceptions about blood glucose testing in tight glycemic control. Am J Crit Care. 2006;15(4):370-7.

235. Carayon P, Gurses A. A human factors engineering conceptual framework of nursing workload and patient safety in intensive care units. Intensive Crit Care Nurs. 2005;21(5):284-301.

236. Carayon P, Wetterneck TB, Rivera-Rodriguez AJ, Hundt AS, Hoonakker P, Holden R, Gurses AP. Human factors systems approach to healthcare quality and patient safety. Appl Ergon. 2014;45(1):14-25.

237. Cobelli C, Renard E, Kovatchev B. The artificial pancreas: a digital-age treatment for diabetes. Lancet Diabetes Endocrinol. 2014;2(9):679-81.

238. DelFavero S, Place J, Kropff J, Messori M, Keith-Hynes P, Visentin R, Monaro M, Galasso S, Boscari F, Toffanin C, Di Palma F, Lanzola G, Scarpellini S, Farret A, Kovatchev B, Avogaro A, Bruttomesso D, Magni L, DeVries JH, Cobelli C, Renard $\mathrm{E}$, Consortium APh. Multicenter outpatient dinner/overnight reduction of hypoglycemia and increased time of glucose in target with a wearable artificial pancreas using modular model predictive control in adults with type 1 diabetes. Diabetes Obes Metab. 2015;17(5):468-76.

239. Kovatchev BP, Renard E, Cobelli C, Zisser HC, Keith-Hynes P, Anderson SM, Brown SA, Chernavvsky DR, Breton MD, Mize LB, Farret A, Place J, Bruttomesso D, Del Favero S, Boscari F, Galasso S, Avogaro A, Magni L, Di Palma F, Toffanin C, Messori M, Dassau E, Doyle FJ 3rd. Safety of outpatient closed-loop control: first randomized crossover trials of a wearable artificial pancreas. Diabetes Care. 2014;37(7):1789-96.

240. Kropff J, Del Favero S, Place J, Toffanin C, Visentin R, Monaro M, Messori M, Di Palma F, Lanzola G, Farret A, Boscari F, Galasso S, Magni P, Avogaro A, Keith-Hynes P, Kovatchev BP, Bruttomesso D, Cobelli C, DeVries JH, Renard E, Magni L, Consortium APh. 2 month evening and night closed-loop glucose control in patients with type 1 diabetes under free-living conditions: a randomised crossover trial. Lancet Diabetes Endocrinol. 2015;3(12):939-47.

241. Thabit H, Hartnell S, Allen JM, Lake A, Wilinska ME, Ruan Y, Evans ML, Coll AP, Hovorka R. Closed-loop insulin delivery in inpatients with type 2 diabetes: a randomised, parallel-group trial. Lancet Diabetes Endocrinol. 2017;5(2):117-24.

242. Kovatchev B, Cheng P, Anderson SM, Pinsker JE, Boscari F, Buckingham BA, Doyle FJ 3rd, Hood KK, Brown SA, Breton MD, Chernavvsky D, Bevier WC, Bradley PK, Bruttomesso D, Del Favero S, Calore R, Cobelli C, Avogaro A, Ly TT, Shanmugham S, Dassau E, Kollman C, Lum JW, Beck RW. Feasibility of long-term closed-loop control: a multicenter 6-month trial of 24/7 automated insulin delivery. Diabetes Technol Ther. 2017;19(1):18-24.

243. Buckingham BA, Bailey TS, Christiansen M, Garg S, Weinzimer S, Bode B, Anderson SM, Brazg R, Ly T, Kaufman FR. Evaluation of a predictive low-glucose management system in-clinic. Diabetes Technol Ther. 2017;19:288-92. 
244. Barnard KD, Wysocki T, Ully V, Mader JK, Pieber TR, Thabit H, Tauschmann M, Leelarathna L, Hartnell S, Acerini CL, Wilinska ME, Dellweg S, Benesch C, Arnolds S, Holzer M, Kojzar H, Campbell F, Yong J, Pichierri J, Hindmarsh P, Heinemann L, Evans ML, Hovorka R. Closing the loop in adults, children and adolescents with suboptimally controlled type 1 diabetes under free living conditions: a psychosocial substudy. J Diabetes Sci Technol (Online). 2017;11:1080-8.

245. Renard E, Farret A, Kropff J, Bruttomesso D, Messori M, Place J, Visentin R, Calore R, Toffanin C, Di Palma F, Lanzola G, Magni P, Boscari F, Galasso S, Avogaro A, Keith-Hynes P, Kovatchev B, Del Favero S, Cobelli C, Magni L, DeVries $\mathrm{JH}$, Consortium APh. Day-and-night closed-loop glucose control in patients with type 1 diabetes under free-living conditions: results of a single-arm 1-month experience compared with a previously reported feasibility study of evening and night at home. Diabetes Care. 2016;39(7):1151-60.

246. Lewis D, Leibrand S, Open APSC. Real-world use of open source artificial pancreas systems. J Diabetes Sci Technol (Online). 2016;10(6):1411.

247. Kovatchev B, Tamborlane WV, Cefalu WT, Cobelli C. The artificial pancreas in 2016: a digital treatment ecosystem for diabetes. Diabetes Care. 2016;39(7):1123-6.

248. Cobelli C, Renard E, Kovatchev BP, Keith-Hynes P, Ben Brahim N, Place J, Del Favero S, Breton M, Farret A, Bruttomesso D, Dassau E, Zisser H, Doyle FJ 3rd, Patek SD, Avogaro A. Pilot studies of wearable outpatient artificial pancreas in type 1 diabetes. Diabetes Care. 2012;35(9):e65-7.

249. Thabit H, Tauschmann M, Allen JM, Leelarathna L, Hartnell S, Wilinska ME, Acerini CL, Dellweg S, Benesch C, Heinemann L, Mader JK, Holzer M, Kojzar H, Exall J, Yong J, Pichierri J, Barnard KD, Kollman C, Cheng P, Hindmarsh PC, Campbell FM, Arnolds S, Pieber TR, Evans ML, Dunger DB, Hovorka R, Consortium AP, Consortium APh. Home use of an artificial beta cell in type 1 diabetes. N Engl J Med. 2015;373(22):2129-40.

250. Wernerman J, Desaive T, Finfer S, Foubert L, Furnary A, Holzinger U, Hovorka R, Joseph J, Kosiborod M, Krinsley J, Mesotten D, Nasraway S, Rooyackers O, Schultz MJ, Van Herpe T, Vigersky RA, Preiser JC. Continuous glucose control in the ICU: report of a 2013 round table meeting. Crit Care. 2014;18(3):226.

251. Holzinger U, Warszawska J, Kitzberger R, Wewalka M, Miehsler W, Herkner H, Madl C. Real-time continuous glucose monitoring in critically ill patients: a prospective randomized trial. Diabetes Care. 2010;33(3):467-72.

252. Auffray C, Balling R, Barroso I, Bencze L, Benson M, Bergeron J, Bernal-Delgado E, Blomberg N, Bock C, Conesa A, Del Signore S, Delogne C, Devilee P, Di Meglio A, Eijkemans M, Flicek P, Graf N, Grimm V, Guchelaar HJ, Guo YK, Gut IG, Hanbury A, Hanif S, Hilgers RD, Honrado A, Hose DR, Houwing-Duistermaat J, Hubbard T, Janacek SH, Karanikas H, Kievits T, Kohler M, Kremer A, Lanfear J, Lengauer T, Maes E, Meert T, Muller W, Nickel D, Oledzki P, Pedersen B, Petkovic M, Pliakos K, Rattray M, Schneider R, Sengstag T, Serra-Picamal X, Spek W, Vaas LA, van Batenburg O, Vandelaer M, Varnai P, Villoslada P, Vizcaino JA, Wubbe JP, Zanetti G. Making sense of big data in health research: towards an EU action plan. Genome Med. 2016;8(1):71.

253. Duarte AM, Psomopoulos FE, Blanchet C, Bonvin AM, Corpas M, Franc A, Jimenez RC, de Lucas JM, Nyronen T, Sipos G, Suhr SB. Future opportunities and trends for e-infrastructures and life sciences: going beyond the grid to enable life science data analysis. Front Genet. 2015;6:197.

254. Mari A, Valerio A. A circulatory model for the estimation of insulin sensitivity. Control Eng Pract. 1997;5(12):1747-52.

255. Andreassen S, Benn JJ, Hovorka R, Olesen KG, Carson ER. A probabilistic approach to glucose prediction and insulin dose adjustment: description of metabolic model and pilot evaluation study. Comput Methods Programs Biomed. 1994;41(3-4):153-65.

256. Arleth T, Andreassen S, Orsini Federici M, Timi A, Massi-Benedetti M. A model of glucose absorption from mixed meals. In: Modelling and control of biomedical systems 2000 (including biological systems): a proceedings volume from the 4th IFAC symposium. Oxford: Elsevier Science Limited; 2000. p. 307-12.

257. Lehmann ED, Deutsch T. AIDA2: a Mk. II automated insulin dosage advisor. J Biomed Eng. 1993;15:201-11.

258. Sundaresan A, Chase JG. Positive end expiratory pressure in patients with acute respiratory distress syndromethe past, present and future. Biomed Signal Process Control. 2011;7(2):93-103.

259. Pretty C, Chase JG, Le Compte A, Lin J, Shaw G. Impact of metoprolol on insulin sensitivity in the ICU. Trauma. 2011;4:4.

260. van Drunen EJ, Chase JG, Chiew YS, Shaw GM, Desaive T. Analysis of different model-based approaches for estimating dFRC for real-time application. Biomed Eng Online. 2013;12:9.

261. Drunen V, Chiew Y, Zhao Z, et al. Visualisation of time-variant respiratory system elastance in ARDS models. Biomed Eng Biomedizinische Technik. 2013. https://doi.org/10.1515/bmt-2013-4328.

262. Chiew YS, Chase JG, Lambermont B, Roeseler J, Pretty C, Bialais E, Sottiaux T, Desaive T. Effects of neurally adjusted ventilatory assist (NAVA) levels in non-invasive ventilated patients: titrating NAVA levels with electric diaphragmatic activity and tidal volume matching. Biomed Eng Online. 2013;12:61.

263. van Drunen EJ, Chiew YS, Chase JG, Shaw GM, Lambermont B, Janssen N, Damanhuri NS, Desaive T. Expiratory model-based method to monitor ARDS disease state. Biomed Eng Online. 2013;12:57.

264. Stahl CA, Moeller K, Steinmann D, Henzler D, Lundin S, Stenqvist O. Determination of 'recruited volume' following a PEEP step is not a measure of lung recruitability. Acta Anaesthesiol Scand. 2015;59(1):35-46.

265. Revie J, Stevenson D, Chase JG, Pretty C, Lambermont B, Ghuysen A, Kolh P, Shaw GM, Desaive T. Evaluation of a model-based hemodynamic monitoring method in a porcine study of septic shock. Comput Math Methods Med. 2013;2013:17.

266. Smith BW, Chase JG, Nokes RI, Shaw GM, Wake G. Minimal haemodynamic system model including ventricular interaction and valve dynamics. Med Eng Phys. 2004;26(2):131-9.

267. Smith BW, Geoffrey Chase J, Shaw GM, Nokes RI. Experimentally verified minimal cardiovascular system model for rapid diagnostic assistance. Control Eng Pract. 2005;13(9):1183-93.

268. Starfinger C, Chase J, Hann C, Shaw G, Lambermont B, Ghuysen A, Kolh P, Dauby P, Desaive T. Model-based identification and diagnosis of a porcine model of induced endotoxic shock with hemofiltration. Math Biosci. 2008;216(2):132-9. 
269. Antonelli M, Levy M, Andrews PJ, Chastre J, Hudson LD, Manthous C, Meduri GU, Moreno RP, Putensen C, Stewart T, Torres A. Hemodynamic monitoring in shock and implications for management. International consensus conference, Paris, France, 27-28 April 2006. Intensive Care Med. 2007;33(4):575-90.

270. Evans A, Le Compte A, Tan CS, Ward L, Steel J, Pretty CG, Penning S, Suhaimi F, Shaw GM, Desaive T. Stochastic targeted (STAR) glycemic control: design, safety, and performance. J Diabetes Sci Technol. 2012;6(1):102-15.

271. Le Compte AJ, Chase JG, Lynn A, Hann CE, Shaw GM, Lin J. Development of blood glucose control for extremely premature infants. Comput Methods Programs Biomed. 2011;102(2):181-91.

272. Lonergan T, LeCompte A, Willacy M, Chase JG, Shaw GM, Wong XW, Lotz T, Lin J, Hann CE. A simple insulin-nutrition protocol for tight glycemic control in critical illness: development and protocol comparison. Diabetes Technol Ther. 2006;8(2):191-206.

273. Dubois J, Van Herpe T, van Hooijdonk RT, Wouters R, Coart D, Wouters P, Van Assche A, Veraghtert G, De Moor B, Wauters J, Wilmer A, Schultz MJ, Van den Berghe G, Mesotten D. Software-guided versus nurse-directed blood glucose control in critically ill patients: the LOGIC-2 multicenter randomized controlled clinical trial. Crit Care. 2017;21(1):212.

274. Chase JG, Shaw GM, Lotz T, LeCompte A, Wong J, Lin J, Lonergan T, Willacy M, Hann CE. Model-based insulin and nutrition administration for tight glycaemic control in critical care. Curr Drug Deliv. 2007;4(4):283-96.

275. Wilinska ME, Blaha J, Chassin L, Cordingley JJ, Dormand NC, Ellmerer M, Haluzik M, Plank J, Vlasselaers D, Wouters PJ, Hovorka R. Evaluating glycemic control algorithms by computer simulations. Diabetes Technol Ther. 2011;13(7):713-22.

276. Van Herpe T, Pluymers B, Espinoza M, Van den Berghe G, De Moor B. A minimal model for glycemia control in critically ill patients. Conf Proc IEEE Eng Med Biol Soc. 2006;1:5432-5.

277. Pretty CG, Chase JG, Le Compte A, Shaw GM, Signal M. Hypoglycemia detection in critical care using continuous glucose monitors: an in silico proof of concept analysis. J Diabetes Sci Technol (Online). 2010;4(1):15-24.

278. Chase JG, Hann CE, Jackson M, Lin J, Lotz T, Wong XW, Shaw GM. Integral-based filtering of continuous glucose sensor measurements for glycaemic control in critical care. Comput Methods Programs Biomed. 2006;82(3):238-47.

279. Zhou T, Dickson JL, Shaw GM, Chase JG. Continuous glucose monitoring measures can be used for glycemic control in the ICU: an in-silico study. J Diabetes Sci Technol (Online). 2018;12(1):7-19.

280. Zhou T, Dickson JL, Geoffrey Chase J. Autoregressive modeling of drift and random error to characterize a continuous intravascular glucose monitoring sensor. J Diabetes Sci Technol (Online). 2018;12(1):90-104.

281. Breton M, Kovatchev B. Analysis, modeling, and simulation of the accuracy of continuous glucose sensors. J Diabetes Sci Technol (Online). 2008;2(5):853-62.

282. Facchinetti A, Del Favero S, Sparacino G, Castle JR, Ward WK, Cobelli C. Modeling the glucose sensor error. IEEE Trans Biomed Eng. 2014;61(3):620-9.

283. Facchinetti A, Del Favero S, Sparacino G, Cobelli C. Model of glucose sensor error components: identification and assessment for new Dexcom G4 generation devices. Med Biol Eng Comput. 2015;53(12):1259-69.

284. Facchinetti A, Del Favero S, Sparacino G, Cobelli C. Modeling transient disconnections and compression artifacts of continuous glucose sensors. Diabetes Technol Ther. 2016;18(4):264-72.

285. Thomas F, Signal M, Harris DL, Weston PJ, Harding JE, Shaw GM, Chase JG, Group CS. Continuous glucose monitoring in newborn infants: how do errors in calibration measurements affect detected hypoglycemia? J Diabetes Sci Technol (Online). 2014;8(3):543-50.

286. Facchinetti A, Sparacino G, Cobelli C. Modeling the error of continuous glucose monitoring sensor data: critical aspects discussed through simulation studies. J Diabetes Sci Technol (Online). 2010;4(1):4-14.

287. Facchinetti A, Sparacino G, Guerra S, Luijf YM, DeVries JH, Mader JK, Ellmerer M, Benesch C, Heinemann L, Bruttomesso D, Avogaro A, Cobelli C, Consortium APh. Real-time improvement of continuous glucose monitoring accuracy: the smart sensor concept. Diabetes Care. 2013;36(4):793-800.

288. Vettoretti M, Facchinetti A, Del Favero S, Sparacino G, Cobelli C. Online calibration of glucose sensors from the measured current by a time-varying calibration function and bayesian priors. IEEE Trans Biomed Eng. 2016;63(8):1631-41.

289. Campos-Nanez E, Breton MD. Effect of BGM accuracy on the clinical performance of CGM: an in-silico study. J Diabetes Sci Technol (Online). 2017;1 1(6):1196-206.

290. Kovatchev BP, King C, Breton M, Anderson S, Clarke W. Clinical assessment and mathematical modeling of the accuracy of continuous glucose sensors (CGS). Conf Proc IEEE Eng Med Biol Soc. 2006;1:71-4.

291. Biagi L, Ramkissoon CM, Facchinetti A, Leal Y, Vehi J. Modeling the error of the medtronic paradigm veo enlite glucose sensor. Sensors (Basel). 2017;17(6):1361

292. Gunn CA, Dickson JL, Hewett JN, Lynn A, Rose HJ, Clarkson SH, Shaw GM, Chase JG. Nasogastric aspiration as an indicator for feed absorption in model-based glycemic control in neonatal intensive care. J Diabetes Sci Technol (Online). 2013;7(3):717-26.

293. Gunn CA, Dickson JL, Pretty CG, Alsweiler JM, Lynn A, Shaw GM, Chase JG. Brain mass estimation by head circumference and body mass methods in neonatal glycaemic modelling and control. Comput Methods Programs Biomed. 2014;115(2):47-54.

294. Dickson JL, Hewett JN, Gunn CA, Lynn A, Shaw GM, Chase JG. On the problem of patient-specific endogenous glucose production in neonates on stochastic targeted glycemic control. J Diabetes Sci Technol (Online). 2013;7(4):913-27.

295. Dickson JL, Chase JG, Pretty CG, Gunn CA, Alsweiler JM. Hyperglycaemic preterm babies have sex differences in insulin secretion. Neonatology. 2015;108(2):93-8.

296. Tekwani S, Murugan R. 'To prone or not to prone' in severe ARDS: questions answered, but others remain. Crit Care. 2014;18(3):305.

297. Abroug F, Ouanes-Besbes L, Dachraoui F, Ouanes I, Brochard L. An updated study-level meta-analysis of randomised controlled trials on proning in ARDS and acute lung injury. Crit Care. 2011;15(1):R6. 
298. Stewart KW, Pretty CG, Tomlinson H, Thomas FL, Homlok J, Noemi SN, Illyes A, Shaw GM, Benyo B, Chase JG. Safety, efficacy and clinical generalization of the STAR protocol: a retrospective analysis. Ann Intensive Care. 2016;6(1):24.

299. Lonergan T, Compte AL, Willacy M, Chase JG, Shaw GM, Hann CE, Lotz T, Lin J, Wong XW. A pilot study of the SPRINT protocol for tight glycemic control in critically III patients. Diabetes Technol Ther. 2006;8(4):449-62.

300. Visentin R, Man CD, Cobelli C. One-day Bayesian cloning of type 1 diabetes subjects: toward a single-day UVA/ Padova type 1 diabetes simulator. IEEE Trans Biomed Eng. 2016;63(11):2416-24.

301. Vettoretti M, Facchinetti A, Sparacino G, Cobelli C. Type 1 diabetes patient decision simulator for in silico testing safety and effectiveness of insulin treatments. IEEE Trans Biomed Eng. 2017. https://doi.org/10.1109/ TBME.2017.2746340

302. Dickson JL, Stewart KW, Pretty CG, Flechet M, Desaive T, Penning S, Lambermont BC, Benyo B, Shaw GM, Chase G. Generalisability of a virtual trials method for glycaemic control in intensive care. IEEE Trans Biomed Eng. 2017. https://doi.org/10.1109/TBME.2017.2686432.

303. Xu F, Wang Q, Zhang H, Chen S, Ao H. Use of pulmonary artery catheter in coronary artery bypass graft. Costs and long-term outcomes. PLoS ONE. 2015;10(2):e0117610.

304. Bernard GR, Sopko G, Cerra F, Demling R, Edmunds H, Kaplan S, Kessler L, Masur H, Parsons P, Shure D, Webb C, Weidemann H, Weinmann G, Williams D. Pulmonary artery catheterization and clinical outcomes: national heart, lung, and blood institute and food and drug administration workshop report. Consensus statement. JAMA J Am Med Assoc. 2000;283(19):2568-72.

305. Rajaram SS, Desai NK, Kalra A, Gajera M, Cavanaugh SK, Brampton W, Young D, Harvey S, Rowan K. Pulmonary artery catheters for adult patients in intensive care. Cochrane Database Syst Rev. 2013;2:CD003408.

306. Chatterjee K. The Swan-Ganz catheters: past, present, and future. A viewpoint. Circulation. 2009;1 19(1):147-52.

307. Frazier SK, Skinner GJ. Pulmonary artery catheters: state of the controversy. J Cardiovasc Nurs. 2008;23(2):113-21 (quiz 122-13).

308. Dasta JF, McLaughlin TP, Mody SH, Piech CT. Daily cost of an intensive care unit day: the contribution of mechanical ventilation. Crit Care Med. 2005;33(6):1266-71.

309. Krinsley JS, Jones RL. Cost analysis of intensive glycemic control in critically ill adult patients. Chest. 2006;129(3):644-50.

310. Van den Berghe G, Wouters PJ, Kesteloot K, Hilleman DE. Analysis of healthcare resource utilization with intensive insulin therapy in critically ill patients. Crit Care Med. 2006;34(3):612-6.

Submit your next manuscript to BioMed Central and we will help you at every step:

- We accept pre-submission inquiries

- Our selector tool helps you to find the most relevant journal

- We provide round the clock customer support

- Convenient online submission

- Thorough peer review

- Inclusion in PubMed and all major indexing services

- Maximum visibility for your research

Submit your manuscript at www.biomedcentral.com/submit 